\title{
Washout policies in long-term indwelling urinary catheterisation in adults (Review)
}

Shepherd AJ, Mackay WG, Hagen S

Shepherd AJ, Mackay WG, Hagen S.

Washout policies in long-term indwelling urinary catheterisation in adults.

Cochrane Database of Systematic Reviews 2017, Issue 3. Art. No.: CD004012. DOI: 10.1002/14651858.CD004012.pub5. 
TABLE OF CONTENTS

ABSTRACT 1

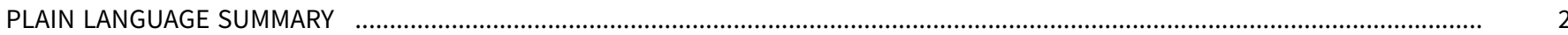

SUMMARY OF FINDINGS

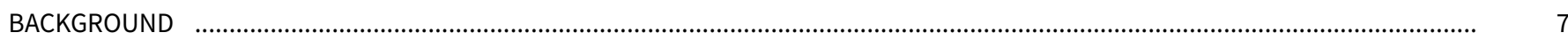

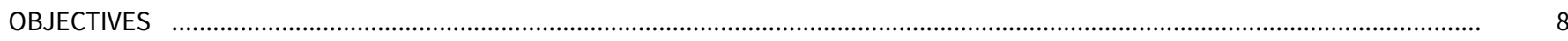

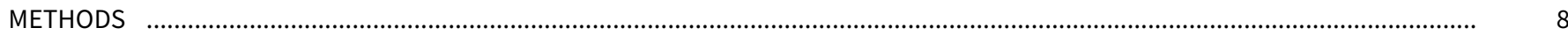

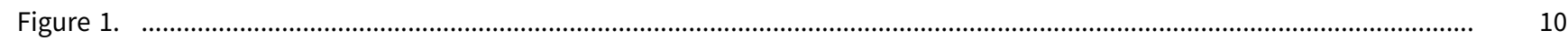

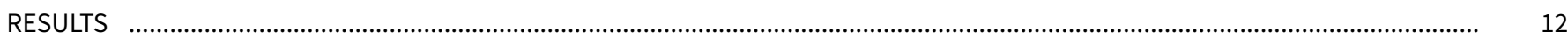

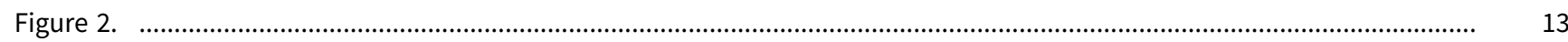

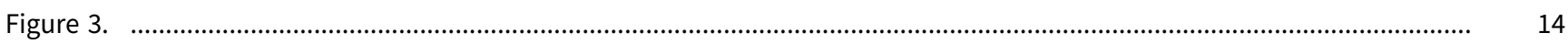

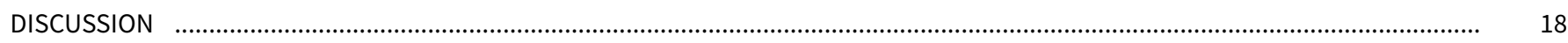

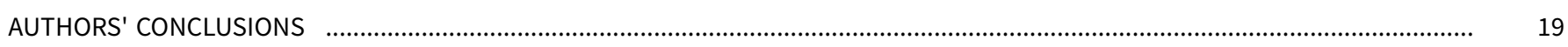

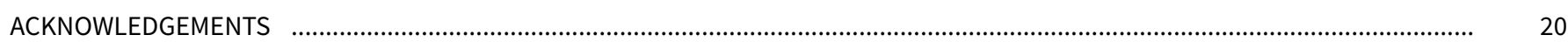

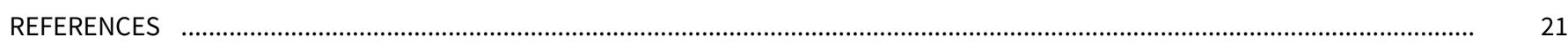

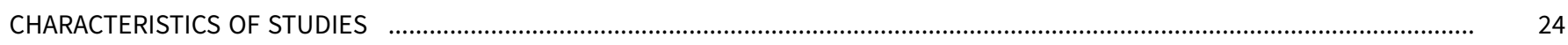

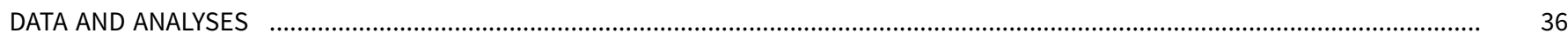

Analysis 1.1. Comparison 1 Any washout versus no washout, Outcome 1 Number of participants with symptomatic UTI. ........ 37

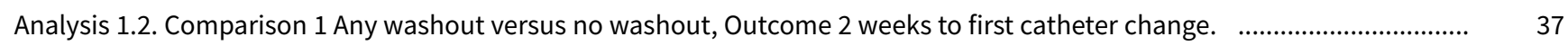

Analysis 1.3. Comparison 1 Any washout versus no washout, Outcome 3 Number of participants needing catheter 37

replacement.

Analysis 1.4. Comparison 1 Any washout versus no washout, Outcome 4 Mean number of episodes of high temperature. ....... 38

Analysis 1.5. Comparison 1 Any washout versus no washout, Outcome 5 Mean number of episodes of high temperature of poss 38 urinary origin.

Analysis 2.1. Comparison 2 One washout solution versus another, Outcome 1 Number of participants with symptomatic UTI. .. 39

Analysis 2.2. Comparison 2 One washout solution versus another, Outcome 2 weeks to first catheter change. ........................

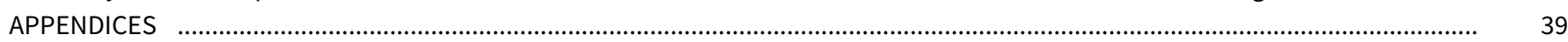

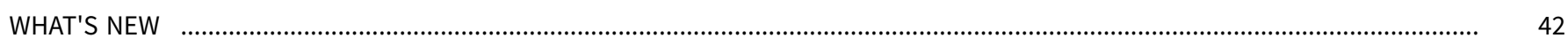

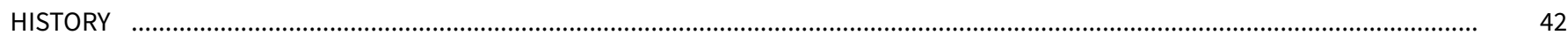

CONTRIBUTIONS OF AUTHORS

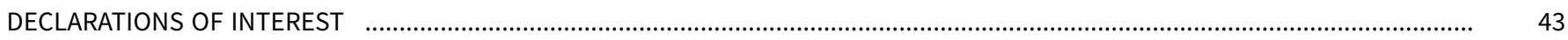

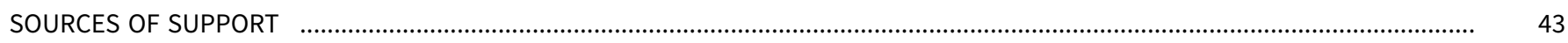

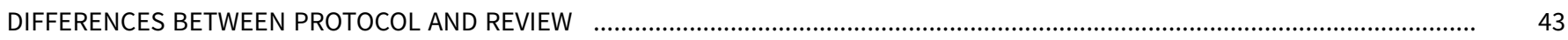

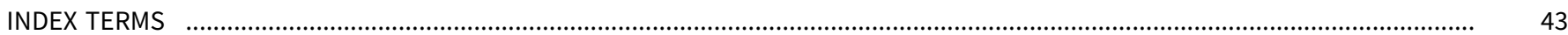


[Intervention Review]

\section{Washout policies in long-term indwelling urinary catheterisation in adults}

Ashley J Shepherd ${ }^{1}$, William G Mackay², Suzanne Hagen 3

1Faculty of Health Sciences and Sport, University of Stirling, Stirling, UK. 2Institute of Healthcare Policy and Practice, Health, Nursing and Midwifery, University of the West of Scotland, Paisley, UK. ${ }^{3}$ Nursing, Midwifery and Allied Health Professions Research Unit, Glasgow Caledonian University, Glasgow, UK

Contact: Ashley J Shepherd, Faculty of Health Sciences and Sport, University of Stirling, Bridge of Allan, Stirling, FK9 4LA, UK. ashley.shepherd@stir.ac.uk.

Editorial group: Cochrane Incontinence Group.

Publication status and date: New search for studies and content updated (no change to conclusions), published in Issue 3, 2017.

Citation: Shepherd AJ, Mackay WG, Hagen S. Washout policies in long-term indwelling urinary catheterisation in adults. Cochrane Database of Systematic Reviews 2017, Issue 3. Art. No.: CD004012. DOI: 10.1002/14651858.CD004012.pub5.

Copyright @ 2017 The Cochrane Collaboration. Published by John Wiley \& Sons, Ltd.

\section{A B S T R A C T}

\section{Background}

People requiring long-term bladder draining with an indwelling catheter can experience catheter blockage. Regimens involving different solutions can be used to wash out catheters with the aim of preventing blockage. This is an update of a review published in 2010.

\section{Objectives}

To determine if certain washout regimens are better than others in terms of effectiveness, acceptability, complications, quality of life and critically appraise and summarise economic evidence for the management of long-term indwelling urinary catheterisation in adults.

\section{Search methods}

We searched the Cochrane Incontinence Group Specialised Trials Register, which contains trials identified from the Cochrane Central Register of Controlled Trials (CENTRAL), MEDLINE, MEDLINE In-Process, MEDLINE Epub Ahead of Print, CINAHL, ClinicalTrials.gov, WHO ICTRP and handsearching of journals and conference proceedings to 23 May 2016. We also examined all reference lists of identified trials and contacted manufacturers and researchers in the field.

\section{Selection criteria}

All randomised and quasi-randomised trials comparing catheter washout policies (e.g. washout versus no washout, different washout solutions, frequency, duration, volume, concentration, method of administration) in adults (aged 16 years and above) in any setting (i.e. hospital, nursing/residential home, community) with an indwelling urethral or suprapubic catheter for more than 28 days.

\section{Data collection and analysis}

Two review authors independently extracted data. Disagreements were resolved by discussion. Data were assessed and analysed as described in the Cochrane Handbook. If data in trials were not fully reported, clarification was sought from the study authors. For categorical outcomes, the numbers reporting an outcome were related to the numbers at risk in each group to derive a risk ratio (RR). For continuous outcomes, means and standard deviations were used to derive mean differences (MD).

\section{Main results}

We included seven trials involving a total of 349 participants, 217 of whom completed the studies. Three were cross-over and four were parallel-group randomised controlled trials (RCTs). Of these, two trials were added for this update (one parallel-group RCT with 40 participants and one cross-over RCT with 67 participants). Analyses of three cross-over trials yielded suboptimal results because they 
were based on between-group differences rather than individual participants' differences for sequential interventions. Two parallel-group trials had limited clinical value: one combined results for suprapubic and urethral catheters and the other provided data for only four participants. Only one trial was free of significant methodological limitations, but there were difficulties with recruitment and maintaining participants in this study.

The included studies reported data on six of the nine primary and secondary outcome measures. None of the trials addressed: number of catheters used, washout acceptability measures (including patient satisfaction, patient discomfort, pain and ease of use), or health status/ measures of psychological health; very limited data were collected for health economic outcomes. Trials assessed only three of the eight intervention comparisons identified. Two trials reported in more than one comparison group.

Four trials compared washout (either saline or acidic solution) with no washout. We are uncertain if washout solutions (saline or acidic), compared to no washout solutions, has an important effect on the rate of symptomatic urinary tract infection or length of time each catheter was in situ because the results are imprecise.

Four trials compared different types of washout solution; saline versus acidic solutions ( 2 trials); saline versus acidic solution versus antibiotic solution (1 trial); saline versus antimicrobial solution (1 trial). We are uncertain if type of washout solution has an important effect on the rate of symptomatic urinary tract infection or length of time each catheter was in situ because the results are imprecise.

One trial compared different compositions of acidic solution (stronger versus weaker solution). We are uncertain if different compositions of acidic solutions has an important effect on the rate of symptomatic urinary tract infection or length of time each catheter was in situ because only 14 participants (of 25 who were recruited) completed this 12 week, three arm trial.

Four studies reported on possible harmful effects of washout use, such as blood in the washout solution, changes in blood pressure and bladder spasms.

There were very few small trials that met the review inclusion criteria. The high risk of bias of the included studies resulted in the evidence being graded as low or very low quality.

\section{Authors' conclusions}

Data from seven trials that compared different washout policies were limited, and generally, of poor methodological quality or were poorly reported. The evidence was not adequate to conclude if washouts were beneficial or harmful. Further rigorous, high quality trials that are adequately powered to detect benefits from washout being performed as opposed to no washout are needed. Trials comparing different washout solutions, washout volumes, and frequencies or timings are also needed.

\section{PLAIN LANGUAGESUMMARY}

\section{How effective are urinary catheter washout solutions?}

\section{Review question}

We aimed to assess effectiveness of urinary catheter washout solutions. This is an update of a review previously published in 2010.

\section{Background}

For a range of reasons, some people are unable to empty their bladders properly or leak urine (urinary incontinence). Urinary catheters, which are soft tubes inserted into the bladder to drain urine to a collection bag, are often used to help people with urinary incontinence. The same type of catheter is used for men and women.

In the UK, about $4 \%$ of people receiving home care, and around $9 \%$ of patients in nursing homes (but possibly up to $40 \%$ in some places), are living with long-term catheters.

Urinary catheter care can be difficult, and problems can occur, especially if used for a long time.

Catheter blockages can occur when kept in place in the bladder for a long time. Blockages may affect half of all people with long-term catheters causing pain and distress. Liquid solutions may be injected into the catheter to prevent or relieve blockages. This is known as a washout. These problems mean that assistance from healthcare professionals is needed for people with urinary catheter blockages.

\section{Search date}

The evidence is current up to 23 May 2016.

\section{Study characteristics}


We included seven studies that presented information on 217 people who completed the studies of 349 who started in the trials. Two studies were new for this update. The studies, published between 1979 and 2014, were conducted in the USA ( 3 studies), the UK ( 2 studies), and one each in Canada and Finland.

The studies included people with long-term catheters. People were allocated randomly to have catheter washouts or not, and the effects compared. We also included studies that compared different types of washout solutions.

Four studies reported on possible harmful effects of washout use, such as blood in the washout solution, changes in blood pressure and bladder spasms.

\section{Study funding sources}

The included studies were funded by Novobay Pharmaceuticals Inc (Linsenmeyer 2014); Alberta Heritage Foundation for Medical Research and the Canadian Nurses Foundation (Moore 2009); National institute of Aging, National Institutes of Health (Muncie 1989); Paralyzed Veterans of America Spinal Cord Research Foundation (Waites 2006). Three studies did not report funding sources.

\section{Key results}

There was not enough good research evidence to determine if catheter washouts were useful.

\section{Quality of the evidence}

The included trials were generally small with methodological flaws. This included limited details on how participants were randomly allocated into groups and how both participants and researchers were blinded to these groups. Evidence quality was low to very low. New trials are needed to definitively answer this research question. 
SUMMARY OF FINDINGS

Summary of findings for the main comparison. Any washout compared to no washout for participants with long-term indwelling urinary catheterisation

Any washout compared to no washout for participants with long-term indwelling urinary catheterisation

Patient or population: Long-term indwelling urinary catheterisation in adults

Settings: Hospital and home

Intervention: Any washout

Comparison: No washout

\begin{tabular}{|c|c|c|c|c|c|c|}
\hline \multirow[t]{3}{*}{ Outcomes } & \multicolumn{2}{|c|}{ Illustrative comparative risks* $(95 \% \mathrm{CI})$} & \multirow{3}{*}{$\begin{array}{l}\text { Relative effect } \\
(95 \% \mathrm{Cl})\end{array}$} & \multirow{3}{*}{$\begin{array}{l}\text { No of Partici- } \\
\text { pants } \\
\text { (studies) }\end{array}$} & \multirow{3}{*}{$\begin{array}{l}\text { Quality of the } \\
\text { evidence } \\
\text { (GRADE) }\end{array}$} & \multirow[t]{3}{*}{ Comments } \\
\hline & Assumed risk & Corresponding risk & & & & \\
\hline & No washout & Any washout & & & & \\
\hline $\begin{array}{l}\text { Symptomatic UTI } \\
\text { (Number of participants with sympto- } \\
\text { matic UTI, citric acid or saline washout } \\
\text { versus no washout) }\end{array}$ & 0 per 1000 & $\begin{array}{l}\text { O per } 1000 \\
(0 \text { to } 0)\end{array}$ & $\begin{array}{l}\text { Not } \\
\text { estimable }\end{array}$ & $\begin{array}{l}53 \\
\text { (1 study) }\end{array}$ & $\begin{array}{l}\oplus \oplus \odot \odot \\
\text { low } 1\end{array}$ & $\begin{array}{l}\text { No participants } \\
\text { met the study } \\
\text { criteria for } \\
\text { symptomatic } \\
\text { UTI }\end{array}$ \\
\hline $\begin{array}{l}\text { Symtomatic UTI } \\
\text { Mean number of episodes of high temper- } \\
\text { ature (saline washout versus no washout) }\end{array}$ & - & $\begin{array}{l}\text { The mean number of } \\
\text { episodes of high tempera- } \\
\text { ture (saline washout versus } \\
\text { no washout) in the interven- } \\
\text { tion groups was: } \\
\mathbf{0 . 7 8} \text { (-0.14 to } 1.70 \text { ) }\end{array}$ & Not estimable & $\begin{array}{l}23 \\
\text { (1 study) }\end{array}$ & $\begin{array}{l}\oplus \odot \Theta \odot \\
\text { very low } 4,5\end{array}$ & \\
\hline Number of catheters used & $\begin{array}{l}526 \text { per } \\
1000\end{array}$ & 353 per 1000 (179 to 689$)$ & $\begin{array}{l}\text { RR 0.67 } \\
\text { (0.34 to } 1.31 \text { ) }\end{array}$ & $\begin{array}{l}40 \\
\text { (1 study) }\end{array}$ & $\begin{array}{l}\oplus \odot \ominus \ominus \\
\text { very low 2,3 }\end{array}$ & \\
\hline
\end{tabular}


(Number of participants needing catheter replacement, saline washout versus no washout)

\begin{tabular}{|c|c|c|c|}
\hline Length of time each catheter was in situ & Not estimable & Not reported & $\begin{array}{l}\text { No data avail- } \\
\text { able }\end{array}$ \\
\hline $\begin{array}{l}\text { Catheter removal rates due to block- } \\
\text { age/infection }\end{array}$ & Not estimable & Not reported & $\begin{array}{l}\text { No data avail- } \\
\text { able }\end{array}$ \\
\hline Rates of asymptomatic bacteriuria & Not estimable & Not reported & $\begin{array}{l}\text { No data avail- } \\
\text { able }\end{array}$ \\
\hline
\end{tabular}

*The basis for the assumed risk (e.g. the median control group risk across studies) is provided in footnotes. The corresponding risk (and its $95 \%$ confidence interval) is based on the assumed risk in the comparison group and the relative effect of the intervention (and its $95 \% \mathrm{Cl}$ ).

Cl: Confidence interval; RR: Risk ratio

GRADE Working Group grades of evidence

High quality: Further research is very unlikely to change our confidence in the estimate of effect.

Moderate quality: Further research is likely to have an important impact on our confidence in the estimate of effect and may change the estimate.

Low quality: Further research is very likely to have an important impact on our confidence in the estimate of effect and is likely to change the estimate.

Very low quality: We are very uncertain about the estimate.

1 Downgraded two levels: The sample size was small $(\mathrm{N}=53)$. Personnel not blinded to allocation of treatment. Blinding of outcome assessment not clear

2 Downgraded two levels: The sample size was small $(\mathrm{N}=40)$. The following were judged to be unclear: Random sequence generation, allocation concealment, blinding of participants and personnel, blinding of outcome assessor, incomplete outcome data and selective reporting).

3 Downgraded one level for imprecision ( $95 \% \mathrm{Cl}$ was very wide: 0.34 to 1.31 ).

4 Downgraded two levels: The sample size was small $(\mathrm{N}=23)$. The following domains were judged to be unclear: Random sequence generation, allocation concealment, and blinding of outcome assessor. Blinding of participants and personnel was judged to be at high risk of bias. Incomplete outcome data and selective reporting was judged to be at low risk of bias).

5 Downgraded one level for imprecision ( $95 \% \mathrm{Cl}-0.14$ to 1.70$)$. Cl was very wide and crossed the line of no effect

6 Downgraded one level for imprecision $(95 \% \mathrm{Cl} 1.02$ to 2.58$)$.

Summary of findings 2 . One washout solution versus another for participants with long-term indwelling urinary catheterisation

One washout solution versus another for participants with long-term indwelling urinary catheterisation

Patient or population: Long-term indwelling urinary catheterisation in adults

Settings: Hospital

Intervention: One washout solution versus another

Outcomes

Illustrative comparative risks*

Relative effect

No of Partici-

Quality of the

Comments

$(95 \% \mathrm{CI})$

$(95 \% \mathrm{Cl})$

pants

evidence

(studies)

(GRADE) 


\begin{tabular}{|c|c|c|c|c|c|c|}
\hline & $\begin{array}{l}\text { Assumed risk } \\
\text { Control }\end{array}$ & $\begin{array}{l}\begin{array}{l}\text { Corresponding } \\
\text { risk }\end{array} \\
\begin{array}{l}\text { One washout } \\
\text { solution versus } \\
\text { another }\end{array}\end{array}$ & & & & \\
\hline $\begin{array}{l}\text { Symptomatic UTI } \\
\text { Number of participants with symptomatic UTI (citric } \\
\text { acid versus saline) }\end{array}$ & 0 per 1000 & $\begin{array}{l}\text { O per } 1000 \\
(0 \text { to } 0)\end{array}$ & Not estimable & $\begin{array}{l}33 \\
\text { (1 study) }\end{array}$ & $\begin{array}{l}\oplus \oplus \Theta \Theta \\
\text { low } 1\end{array}$ & $\begin{array}{l}\text { No participants } \\
\text { met the study crite- } \\
\text { ria for symptomatic } \\
\text { UTI }\end{array}$ \\
\hline $\begin{array}{l}\text { Symtomatic UTI } \\
\text { Mean number of episodes of high temperature }\end{array}$ & & & Not estimable & & Not reported & No data available \\
\hline $\begin{array}{l}\text { Symptomatic UTI } \\
\text { Mean number of episodes of high temperature due } \\
\text { to possible urinary origin }\end{array}$ & & & Not estimable & & Not reported & No data available \\
\hline $\begin{array}{l}\text { Number of catheters used } \\
\text { Number of participants needing catheter replace- } \\
\text { ment }\end{array}$ & & & Not estimable & & Not reported & No data available \\
\hline Length of time each catheter was in situ & & & Not estimable & & Not reported & No data available \\
\hline Catheter removal rates due to blockage/infection & & & Not estimable & & Not reported & No data available \\
\hline Rates of asymptomatic bacteriuria & & & Not estimable & & Not reported & No data available \\
\hline \multicolumn{7}{|c|}{$\begin{array}{l}\text { *The basis for the assumed risk (e.g. the median control group risk across studies) is provided in footnotes. The corresponding risk (and its } 95 \% \text { confidence interval) is } \\
\text { based on the assumed risk in the comparison group and the relative effect of the intervention (and its } 95 \% \mathrm{Cl} \text { ). } \\
\text { Cl: Confidence interval; RR: Risk ratio; }\end{array}$} \\
\hline \multicolumn{7}{|c|}{$\begin{array}{l}\text { GRADE Working Group grades of evidence } \\
\text { High quality: Further research is very unlikely to change our confidence in the estimate of effect. } \\
\text { Moderate quality: Further research is likely to have an important impact on our confidence in the estimate of effect and may change the estimate. } \\
\text { Low quality: Further research is very likely to have an important impact on our confidence in the estimate of effect and is likely to change the estimate. } \\
\text { Very low quality: We are very uncertain about the estimate. }\end{array}$} \\
\hline
\end{tabular}

1 Downgraded two levels: The sample size was small $(\mathrm{N}=33)$. Personnel not blinded to allocation of treatment. Blinding of outcome assessment not clear. 


\section{B A C K G R O U N D}

\section{Description of the condition}

Indwelling catheterisation may be used for people with intractable incontinence or chronic bladder outlet obstruction. People may require long-term urinary catheterisation for a number of reasons: urinary retention (incomplete emptying of the bladder) caused by benign prostatic hyperplasia (enlarged prostate) or prostate tumour, reduced bladder contractility, or urinary incontinence (involuntary leakage of urine) not amenable to toileting, intermittent catheterisation, or any other method of management. People with conditions such as multiple sclerosis, dementia, stroke, spina bifida, and spinal cord injury may be susceptible to these problems.

Numbers of people being managed using long-term catheters is difficult to estimate. Between April and May 2013, 1181 longterm care facilities in Europe participated in a point prevalence survey of healthcare-associated infection and related risk factors. The median percentage of long-term care facility residents with a urinary catheter was $6.3 \%$; the highest percentage of urinary catheterisation was reported in the Czech Republic (33.3\%) (ECDC 2014). The percentage of people receiving care at home with a urinary catheter was estimated to be $5.4 \%$ in another European study (range 0\% to 23\%) (Sørbye 2005). Those using catheters longterm often experience complications such as blockage, leakage and infection. These complications can have significant implications for resource use and quality of life due to increased general practitioner and hospital outpatient appointments, emergency admissions and nursing resource demands (Evans 2000).

\section{Bacterial infection}

Bacteriuria, which occurs when bacteria colonise the urinary tract, is the root cause of catheter-associated complications. Bacteriuria risk increases with days of catheterisation (Garibaldi 1974; Stark 1984); over time, all people with a catheter will develop bacteruria (SIGN 2012). Increased levels of bacteriuria may expose people to increased risk of complications, including catheter-associated urinary tract infection (CAUTI), secondary bacteraemia (blood infection) and infection at other sites, such as the joints. Up to $30 \%$ of long-term catheterised people will become symptomatic and require some intervention (Saint 1999). Bacteriuria and CAUTI are significant problems in long-term care. People with urinary catheters are up to 6.5 times more likely to develop urinary tract infection (Sørbye 2005); the prevalence of CAUTI has been estimated to be $8.5 \%$ (Getliffe 2006).

In an attempt to deal with the problems of bacterial colonisation, encrustations (biofilm) and CAUTI, catheter washouts or irrigations (sometimes called bladder washouts or irrigations) were introduced (Getliffe 2003). Over the last few decades, various antibiotic and antiseptic solutions have been used as washout solutions with the aim of preventing and treating catheterassociated problems. However, evidence about their effectiveness is conflicting. Concerns exist that use of washouts can damage the bladder mucosa and increase infection rates due to opening the closed catheter system. Current UK National Health Service guidelines specify that antibiotic solutions are not effective in treating CAUTI (HIS 2004). Use of antiseptic washouts is also believed to be of little value for the prevention and treatment of CAUTI and is no longer advised in practice (Pellowe 2003).

\section{Catheter blockage}

The most common problem of long-term indwelling catheters is the formation of encrustations on the luminal and outer surfaces of the catheter with consequent blockage and by-passing of urine resulting in urinary leakage. Nearly half of all people with an indwelling catheter experience problems with catheter blockage due to encrustation (Getliffe 1992; Kohler-Ockmore 1996; Kunin 1987; Roe 1987). Blockage of an indwelling catheter is traumatic, causing pain and distress. The most commonly isolated bacteria in blockages is Proteus mirabilis (Stickler 2010), which may cause crystalline deposits (such as calcium phosphate and magnesium ammonium phosphate (struvite)) to build up through a rise in $\mathrm{pH}$ caused by the metabolism of urea to ammonia and bicarbonate (Hesse 1992; Wilks 2015).

\section{Fungal infection}

Candiduria (the presence of Candida species in the urine) can also occur in people with long-term indwelling catheters, and its incidence is directly related to duration of catheterisation, hospitalisation and antibiotic use (Hamory 1978). Candida spp are thought to be the second most common microorganisms causing CAUTI or asymptomatic colonisation in people who are catheterised (Padawer 2015). Candiduria is generally asymptomatic but rare complications can include fungal balls in the bladder or renal pelvis, kidney infection and disseminated candidiasis (infection with Candida spp). Management for people with asymptomatic catheter-associated candiduria is unclear. Removing the catheter results in the disappearance of candiduria in about a third of people. For people who are asymptomatic. but in whom candiduria persists or must remain catheterised, several management techniques have been used, primarily involving oral medication or bladder irrigation. The solutions used and the method of administration (continuous irrigation), in the treatment of fungal infections are very different and hence were not evaluated in this review.

\section{Description of the intervention}

Current practice for the management of people with catheter encrustation and blockage varies but is largely dependent on the use of catheter maintenance solutions. Treatments commonly used for people living in the community include washing out the catheter with saline or acidic solutions or both. However, there is much debate about this practice.

\section{How the intervention might work}

In vitro evidence suggests that normal saline is ineffective in diminishing encrustations but there is some evidence that methenamine preparations and acidic washouts reduce catheter encrustation (Getliffe 1994; Hesse 1989; King 1991). Other research work questions the efficacy of acidification of the urine for preventing catheter encrustation (Bibby 1993). Furthermore, none of the continence advisers questioned in a 1993 study thought that regular washouts were useful compared to $25 \%$ of district nurses who thought they were (Capewell 1993). Despite the controversy surrounding the effectiveness of washouts for managing encrustation and blockage, they are widely used (Pomfret 2004). 


\section{Why it is important to do this review}

There is no consensus regarding the indications for use of catheter washouts nor the method of administration, frequency, duration of administration or choice of solution. The wide variety of solutions available, combined with the multiplicity of possible procedures for their application, and potential risks posed, indicated need for an update of this systematic review. We aimed to summarise the evidence from randomised controlled trials on the use of catheter washouts for the management of adults with long-term indwelling urinary catheters.

\section{OB JECTIVES}

To determine if certain washout regimens are better than others in terms of effectiveness, acceptability, complications, quality of life and critically appraise and summarise economic evidence for the management of long-term indwelling urinary catheterisation in adults.

\section{METHODS}

\section{Criteria for considering studies for this review}

\section{Types of studies}

All randomised or quasi-randomised controlled trials, including cross-over designs, evaluating the use of urinary catheter washouts in long-term catheterised adults.

\section{Types of participants}

Adults, aged at least 16 years, in any setting (i.e. hospital, nursing or residential home, community) with an indwelling urethral, suprapubic or perineal catheter in situ for more than 28 days. Adults whose treatment combined intermittent catheterisation with periods of indwelling catheterisation were included only if the indwelling catheter had been in situ for more than 28 days at the time of data collection.

\section{Types of interventions}

The interventions considered included catheter washouts with water, saline, antiseptic, acidic, antimicrobial or antibiotic solutions alone or in any combination. Studies were considered that compared:

1. washouts with controls who did not receive washouts;

2. washouts with other participants who received different washouts;

3. different washout regimens at different time periods i.e. crossover studies; and

4. different washout regimens i.e. frequency, duration, volume, concentration, method of administration.

Throughout the literature, the terminology used to refer to the 'washing-out' of catheters is somewhat confusing. The term 'washout' tends to be used in the US literature whereas in the UK, catheter washouts are often referred to as 'catheter maintenance solutions' or 'bladder washout' which can cause confusion with bladder irrigation/lavage used after surgery (Getliffe 1996). In this review all trials referring to catheter or bladder washouts were considered with the exception of post-surgical bladder irrigations, therapeutic bladder instillations used, for example, in the treatment of people with cancer, and continuous irrigations with antifungal solutions.

Trials that involved irrigation of catheter drainage bags were not considered in this review. Other types of interventions to prevent or reduce encrustation or infection, such as changes in fluid intake or use of oral prophylactic antibiotics, were also excluded.

We planned to compare:

1. use of any type of catheter washout (e.g. water, saline, antiseptic, antibiotic) versus not using one;

2. one type of catheter washout solution versus another type;

3. clinically or microbiologically indicated washout versus routine washout;

4. long intervals between catheter washouts versus short intervals;

5. one method of administration of catheter washouts (e.g. agitation, gravity, syringe) versus another method;

6. smaller volumes of washout solution versus larger volumes;

7. a stronger solution of washout versus a weaker solution; and

8. a single washout instillation versus two or more sequential washout instillations of the same type.

\section{Types of outcome measures}

\section{Primary outcomes}

Catheter washouts were introduced to prevent or reduce the occurrence of catheter-associated infection. In recent years their use has been primarily aimed at minimising the effects of recurrent encrustation and blockage. Primary outcomes considered were objective measures of catheter-associated urinary tract infection (CAUTI; which ranged in definitions among trials) and catheter blockage. Such measures include:

- symptomatic urinary tract infections (UTIs) (as defined by the trialists);

- number of catheters used;

- length of time each catheter was in situ;

- catheter removal rates due to blockage or infection (definitions of blockage or infection were those used in the trial reports); and

- rates of asymptomatic bacteriuria.

\section{Secondary outcomes}

\section{Washout acceptability measures}

Reported levels of patient discomfort associated with washouts; patient satisfaction with the outcome of washouts (i.e. minimisation of catheter-associated problems, reduction in pain and trauma when the catheter was withdrawn); and ease of use of washouts/washout regimens for patients, their carers and healthcare practitioners were considered.

\section{Health status or measures of psychological health}

Quality of life and psychological outcome indicators as measured by generic validated instruments such as Short Form 36 (SF-36) (Ware 1993) and Hospital Anxiety and Depression Score (HADS) (Zigmond 1983) were sought.

\section{Measures of complications or adverse effects of washouts}

Adverse effects that result at the time of washout administration, such as inability to tolerate washout solution and irritation or 
trauma to urethral or bladder tissue were considered. These effects may be indicated by bypassing or bleeding around the catheter or by volume of red blood cells returned during washout procedure. Use of prophylactic antibiotics and rescue antibiotics were also included.

\section{Health economic outcomes}

Economic measures considered included costs of washouts, resource implications associated with different washouts/washout regimens, and any reports of formal economic evaluations of washouts, such as cost-effectiveness or cost-utility analysis.

\section{Search methods for identification of studies}

We did not impose any language or other limitations on the searches.

\section{Electronic searches}

We searched the Cochrane Incontinence Group Specialised Trials Register for this update. Details of the search methods used to build the Specialised Register are presented in the Group's module in the Cochrane Library. The Register contains trials identified from the Cochrane Central Register of Controlled Trials (CENTRAL), MEDLINE, MEDLINE In-Process, MEDLINE Epub Ahead of Print, CINAHL, ClinicalTrials.gov, WHO ICTRP, UK Clinical Research Network Portfolio and results from handsearching journals and conference proceedings. Many of the trials in the Cochrane Incontinence Group Specialised Register are also contained in CENTRAL. The last search was conducted 23 May 2016.

The terms used to search the Cochrane Incontinence Specialised Register are given in Appendix 1.
Searches performed by the review authors for the 2010 version of this review (Hagen 2010) are detailed in Appendix 2.

\section{Searching other resources}

We searched the reference lists of relevant articles for other possibly relevant trials.

For the 2010 version of the review key researchers in the field of catheter management, and catheter maintenance solution manufacturers (BBraun, Coloplast and Bard) were contacted to identify other possibly relevant trials (Hagen 2010).

We contacted the authors of any ongoing studies to enquire as to whether any results were available (October 2015).

\section{Data collection and analysis}

\section{Selection of studies}

Two review authors (AS, SH) independently screened titles and abstracts for inclusion of all the potential studies identified as a result of the search. We retrieved the full-text study reports and the same two review authors independently screened the full-text to identify studies for inclusion. We recorded reasons for exclusion of the ineligible studies. We resolved disagreements through discussion or, if required, we consulted a third review author (WM). We identified and excluded duplicates and collated multiple reports of the same study so that each study rather than each report was the unit of interest in the review. We recorded the selection process in a PRISMA flow diagram (Figure 1), and Characteristics of excluded studies. 
Figure 1. Study flow diagram

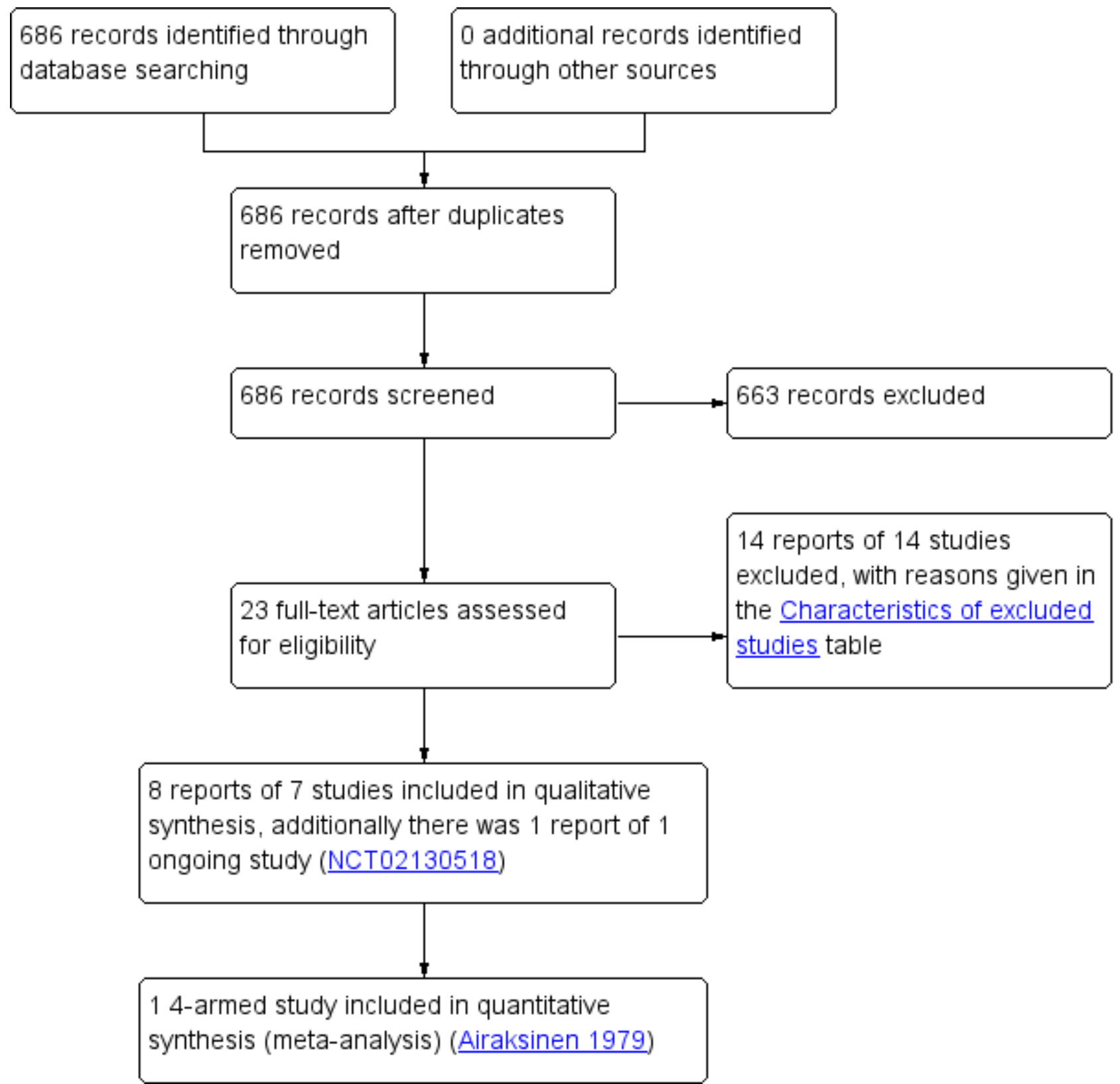

\section{Data extraction and management}

We used a data collection form for study characteristics and outcome data which was used for the 2010 version of this review (Hagen 2010). Two review authors (AS, SH) extracted study characteristics from included studies. We extracted the following study characteristics.

1. Methods: study design, total duration of study, details of any run-in period, number of study centres and location, study setting, withdrawals, random allocation sequence, outcome assessment blinding and date of study.

2. Participants: N, mean age, age range, gender, inclusion criteria, and exclusion criteria.

3. Interventions: intervention, comparison, method of administration.
4. Outcomes: primary and secondary outcomes specified and collected, and time points reported.

5. Notes: funding for trial, and notable conflicts of interest of trial authors.

Two review authors (AS, SH) independently extracted outcome data from included studies. We noted in Characteristics of included studies if outcome data were not reported in a usable way. We resolved disagreements by consensus or by involving a third review author (WM). One review author (SH) transferred data into the Review Manager file (RevMan 2014). We double-checked that data were entered correctly by comparing the data presented in the systematic review with the study reports. A second review author (AS) spot-checked study characteristics for accuracy against the trial report. 


\section{Assessment of risk of bias in included studies}

Two review authors (AS, SH) independently assessed risk of bias for each study using the criteria outlined in the Cochrane Handbook for Systematic Reviews of Interventions (Higgins 2011). We resolved disagreements by discussion or by involving another review author (WM). We assessed the risk of bias according to the following domains.

1. Random sequence generation.

2. Allocation concealment.

3. Blinding of participants and personnel.

4. Blinding of outcome assessment.

5. Incomplete outcome data.

6. Selective outcome reporting.

7. Other bias.

We graded each potential source of bias as high, low or unclear and justified our judgement in the 'Risk of bias' table. We summarised the risk of bias judgements across different studies for each of the domains listed. We considered blinding separately for different key outcomes, where necessary. Where information on risk of bias related to unpublished data or correspondence with a trialist, we noted this in the 'Risk of bias' table.

When considering treatment effects, we took into account the risk of bias for the studies that contribute to that outcome.

\section{Measures of treatment effect}

We intended to enter the outcome data for each study into the data tables in Review Manager 5 to calculate the treatment effects (RevMan 2014). We planned to use risk ratio for dichotomous outcomes, and mean differences or standardised mean differences for continuous outcomes. This was not possible because only single studies were available for analyses.

\section{Unit of analysis issues}

We planned to analyse cross-over trials with continuous outcomes by determining the mean and standard error of the person difference between treatment periods; however, data from crossover trials were not reported appropriately and this was not possible.

\section{Dealing with missing data}

We contacted investigators or study sponsors to verify key study characteristics and obtain missing numerical outcome data where possible. Where this was not possible, and the missing data were thought to introduce serious bias, we planned to explore the impact of including such studies in the overall assessment of results by a sensitivity analysis. However, this was not possible.

\section{Assessment of heterogeneity}

We planned to use the $\mathrm{I}^{2}$ statistic to measure heterogeneity among the trials in each analysis. If we identified substantial heterogeneity, we planned to report it and explore possible causes by prespecified subgroup analysis. However, this was not possible as only single studies were identified.

\section{Assessment of reporting biases}

We planned that if the meta-analysis included more than 10 trials, we would construct a funnel plot to assess reporting biases (Higgins 2011). However, this was not possible.

\section{Data synthesis}

Included trial data were to be analysed as described in the Cochrane Handbook for Systematic Reviews of Interventions (Higgins 2011). It was planned that where possible (only with two independent comparisons from one trial), meta-analysis would be undertaken using a fixed-effect model approach, if there was no evidence of significant heterogeneity. For cross-over trials we planned to analyse data as recommended in section 16.4 of the Handbook. However, no suitable data were available and meta-analysis was not performed.

\section{GRADE and 'Summary of findings' table}

We created 'Summary of findings' tables using clinically important primary outcomes:

- rates of symptomatic UTIs (as defined by the trialists);

- number of catheters used;

- length of time each catheter was in situ;

- catheter removal rates due to blockage or infection (definitions of blockage or infection were those used in the trial reports); and

- rates of asymptomatic bacteriuria.

We used the five GRADE considerations (study limitations, consistency of effect, imprecision, indirectness and publication bias) to assess the quality of the body of evidence as it relates to the studies which contribute data to the meta-analyses for the prespecified outcomes (Atkins 2004). We used methods and recommendations described in Section 8.5 and Chapter 12 of the Cochrane Handbook for Systematic Reviews of Interventions (Higgins 2011) using GRADEpro GDT software (GRADEpro GDT 2015). We justified all decisions to down- or up-grade the quality of studies using footnotes, and made comments to aid the reader's understanding of the review where necessary.

Summary of findings tables were not presented for comparisons where no studies were identified. Presentation of summary of findings tables for these comparisons will be considered in future updates of the review if more data becomes available.

\section{Subgroup analysis and investigation of heterogeneity}

We intended to perform subgroup analysis to explore the impact of subgroups on the intervention. Insufficient data were provided and analyses was not performed.

\section{Sensitivity analysis}

We intended to conduct sensitivity analysis by including or excluding trials we judged as high risk of bias. We did not conduct sensitivity analysis because meta-analysis was not performed. 


\section{RESULTS}

\section{Description of studies}

\section{Results of the search}

The search identified 686 records (Figure 1). Of these, 23 reported potentially eligible studies. Clarification was sought at this stage regarding study characteristics from five study authors: two authors responded, two authors could not be contacted and a response was not received from one author.

This update included two new studies (Airaksinen 1979; Linsenmeyer 2014; 107 participants) to bring the total number of included studies to seven (349 participants randomised). Airaksinen 1979 was identified as a study awaiting assessment in the 2010 review. Four studies were parallel-group randomised controlled trials (RCTs) and included a total of 213 participants (Airaksinen 1979; McNicoll 2003; Moore 2009; Waites 2006) and three were randomised cross-over trials which included a total of 136 participants (Kennedy 1992; Linsenmeyer 2014; Muncie 1989). Three studies were conducted in the USA (Linsenmeyer 2014; Muncie 1989; Waites 2006), two in the UK (Kennedy 1992; McNicoll 2003), and one each in Canada (Moore 2009) and Finland (Airaksinen 1979).

One study (NCT02130518) is ongoing and results are not yet available (see Characteristics of ongoing studies).

\section{Included studies}

\section{Participants}

Airaksinen 1979 studied 40 participants (16 males, 24 females) who were recruited from a Finnish health service centre and were randomly assigned into four groups (two experimental and two control). Washouts were withheld in the control groups.

Kennedy 1992 studied 25 elderly women from three UK hospitals who were long-term catheterised. This study comprised a withinpatient comparison of three different solutions (saline, citric acid $3.23 \%$, citric acid 6\%). Participants received all three washout solutions but in different orders.

Linsenmeyer 2014 studied 67 adults with neurogenic bladder who had long-term indwelling transurethral or suprapubic urinary catheters in this multicentre study conducted in the USA. This study compared the use of an antimicrobial washout solution with saline. The study was funded by Novobay Pharmaceuticals.

McNicoll 2003 studied 11 people in this UK-based study who were living in the community with long-term catheters known to block with encrustation. This study compared the use of citric acid washouts with planned catheter changes.

Moore 2009 studied 73 (36 males, 37 females) Canadian community-dwelling or long-term care adults with long-term indwelling catheters that required changing every three weeks or less, requiring supportive or continuing care. Participants were randomly assigned to one of three groups: control (usual care, no washout), saline washout or acidic washout. The study was funded by the Alberta Heritage Foundation for Medical Research and the Canadian Nurses Foundation.
Muncie 1989 studied 44 long-term hospitalised female patients at one centre in Baltimore USA, aged 18 years or more who had indwelling urethral catheters in place for 30 consecutive days or longer. This randomised cross-over trial compared saline washout with no washout and was funded by the National Institutes of Health.

Waites 2006 randomised 89 community-residing patients (49 male, 40 female) in this USA-based study with neurogenic bladder managed by indwelling catheter. This trial compared twice daily washout using one of three different solutions (saline, acetic acid, neomycin-polymyxin). This study was funded by the Paralyzed Vetrans of America Spinal Cord Research Foundation.

\section{Interventions}

Three trials compared washout (using saline and/or acidic solution) with no washout (Airaksinen 1979; Moore 2009; Muncie 1989). Three trials compared different types of washout solution (Kennedy 1992; Linsenmeyer 2014; Waites 2006). Kennedy 1992 included a comparison of alternative compositions of an acidic solution, and Linsenmeyer 2014 compared an antimicrobial solution with saline. McNicoll 2003 compared washout use with planned catheter removal. The protocol for the planned catheter removal group in McNicoll 2003 was not described, but varied from patient to patient. McNicoll 2003 was included in analyses comparing washout versus no washout.

\section{Washout versus no washout}

Moore 2009 reported that participants were randomised to one of three groups: usual care with no washout; weekly catheter washout with $50 \mathrm{~mL}$ sterile normal saline; and weekly catheter washout with $50 \mathrm{~mL}$ sterile Contisol (also known as Suby G) (citric acid 3.23\%). Study endpoints were eight weeks, three or more catheter changes, or symptomatic UTI requiring antibiotics.

Muncie 1989 compared 10 weeks of once daily normal saline washout ( $30 \mathrm{~mL}$ via syringe) with 10 weeks of no washout. New catheters were inserted at the beginning and end of each study phase, and drainage bags were changed weekly in both groups. The intervention duration was 24 weeks (2-week no washout runin period, 10-week washout or no washout phase, and 2-week no intervention period before entering alternate phase).

Airaksinen 1979 randomised 40 patients to four groups of 10 participants. Group 1 had Silicath catheter with regular wash out; group 2 also had Silicath catheter but without washout; group 3 had Silastic catheter with wash out; and group 4 had Silastic catheter but without washout. Those groups who received the washout had this at two week intervals with normal saline; the volume used was $10 \mathrm{~mL}$ or $20 \mathrm{~mL}$ depending on the size of the catheter.

McNicoll 2003 included two parallel groups: daily instillation of citric acid catheter maintenance solution, and planned catheter removal. The volume of solution and method of administration in the washout group were not stated. The control group were to receive "planned catheter changes" but the protocol was not described and this varied among patients. The intervention duration was 12 weeks.

\section{Different types of solution}

Three types of solution were evaluated in Kennedy 1992: three weeks of twice weekly washout with $0.9 \%$ sodium chloride 
(saline); three weeks of twice weekly washout with Suby G; three weeks of twice weekly washout with Solution R (citric acid 6\%, gluconolactone $0.6 \%$, light magnesium carbonate $2.8 \%$, disodium edetate $0.01 \%)$. All washouts were administered by attaching a 100 $\mathrm{mL}$ sterile, pre-packed sachet to the catheter and allowing it to drain into the bladder via gravity. The intervention duration was 12 weeks (1-week normal saline washout run-in period, plus a 3week phase with each of the solutions, and 1-week normal saline washout between solutions).

Waites 2006 compared three solutions: eight weeks of twice daily normal saline washout; eight weeks of twice daily $0.25 \%$ acetic acid washout; and eight weeks of twice daily neomycin-polymyxin GU washout (containing $40 \mathrm{mg} / \mathrm{mL}$ neomycin sulphate and 200,000 $\mathrm{U} / \mathrm{mL}$ polymyxin $\mathrm{B}$ ). At each washout, $30 \mathrm{~mL}$ of the irrigant was instilled for 20 minutes via a syringe.

Moore 2009 had three arms and provided a comparison of saline and Contisol washout solutions in addition to a washout versus no washout comparison.

Linsenmeyer 2014 compared different treatment regimens: $0.2 \%$ auriclosene in preliminary formulation was dosed for over 2 weeks (3 times/week), 0.2\% auriclosene was dosed on the same schedule, $0.2 \%$ auriclosene twice weekly over four weeks. The control was saline. Participants were randomised to one irrigation solution for the first treatment regimen and after a washout period, irrigated with the other solution.

\section{Figure 2. Methodological quality graph: review authors' judgements about each methodological quality item} presented as percentages across all included studies

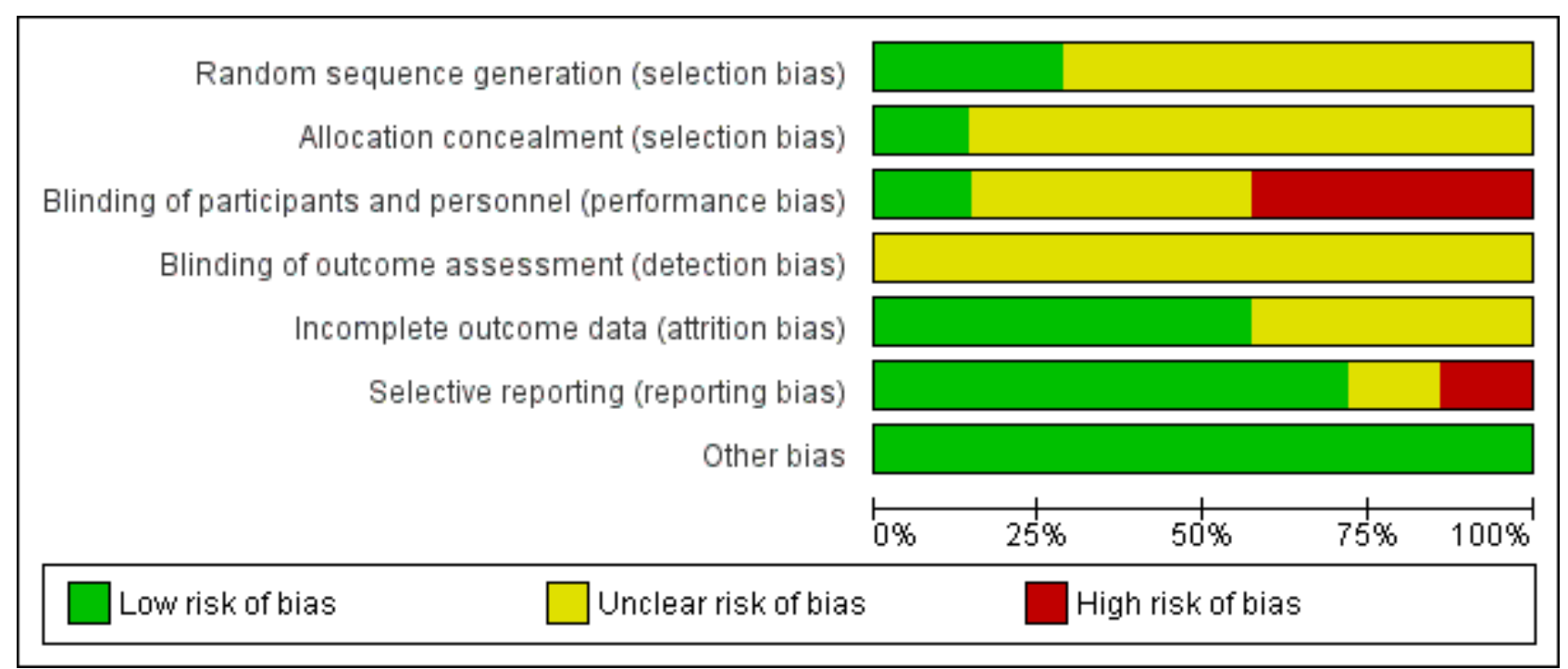

Washout policies in long-term indwelling urinary catheterisation in adults (Review)

\section{A stronger solution of washout versus a weaker solution}

In Kennedy 1992, two groups received washouts with different compositions of acidic solution: one solution contained $3.23 \%$ citric acid (Suby G) and the other 6\% citric acid (Solution R). However, other chemical components of the two solutions also differed.

\section{Excluded studies}

See Characteristics of excluded studies. We excluded 14 studies; the most common reasons for exclusion were that participants were not catheterised for more than 28 days or the study was not an RCT (Andersson 1986; Bach 1990; Bruun 1978; Davies 1987; Elliott 1989; Elliott 1990; Furuno 1998; Gelman 1980; Kennedy 1984; Meyers 1964; Robertson 1990; Ruwaldt 1983; Vainrub 1977; Warren 1978).

\section{Ongoing studies}

One randomised, double-blinded study (NCT02130518) is currently ongoing and aims to compare the use of $0.2 \%$ auriclosene solution ( 8 treatments over 4 weeks) with a placebo comparator auriclosene vehicle solution ( 8 treatments over 4 weeks). Authors were contacted and responded that no results for this trial were currently available. This study is being conducted in the USA and is funded by NovoBay Pharmaceuticals. Further details are presented in Characteristics of ongoing studies.

\section{Risk of bias in included studies}

All but one trial had at least one factor associated with risk of bias (Figure 2; Figure 3). 
Figure 3. Methodological quality summary: review authors' judgements about each methodological quality item for each included study

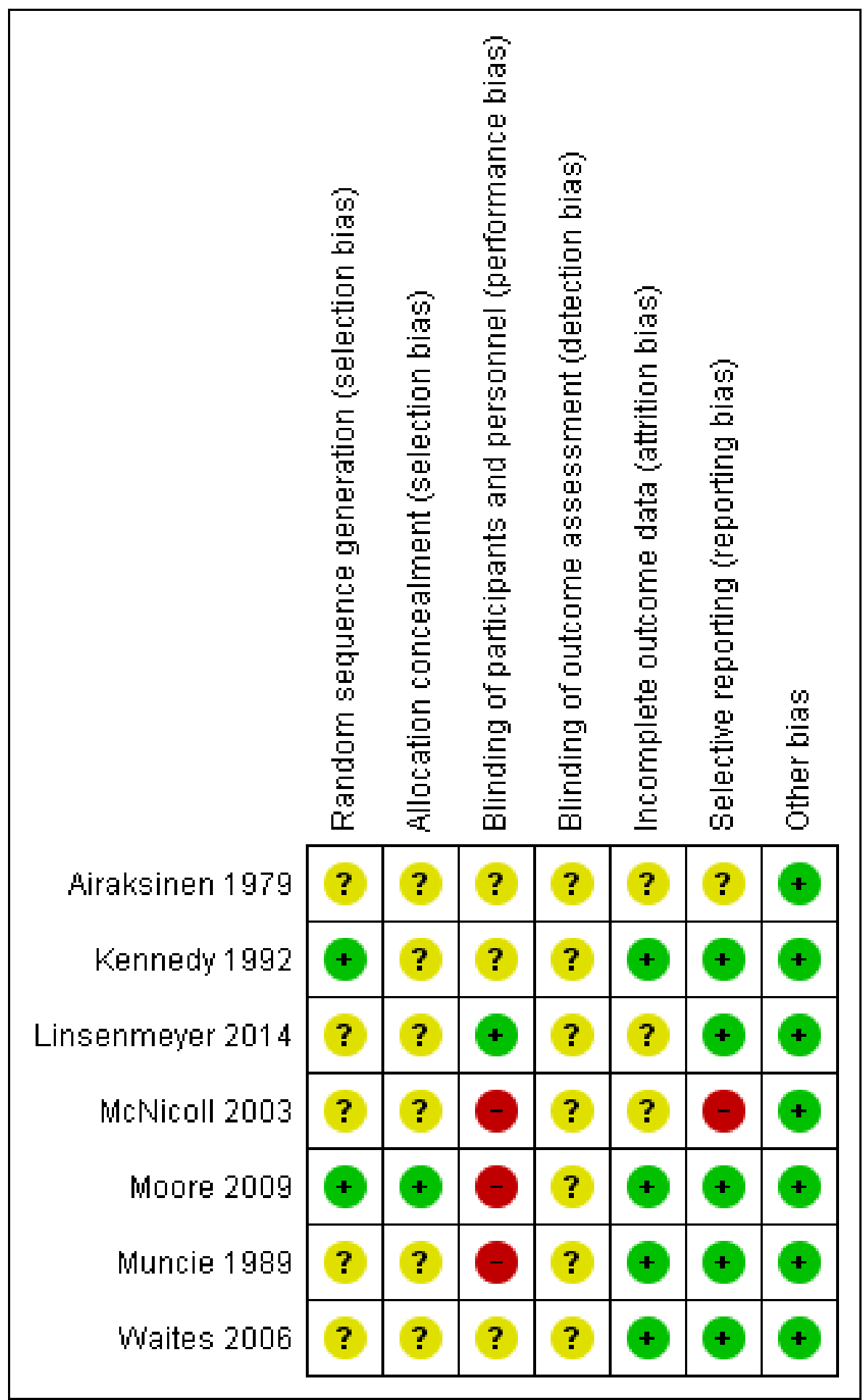

\section{Allocation}

Little information was provided about the process of concealment of group allocation in most included trials. In Kennedy 1992 it was assumed the allocation process was not concealed because random number tables were used to determine the order in which participants received the three solutions; this study was assessed at unclear risk of bias. Five studies indicated that participants were randomly allocated to study groups, but details were not provided (Airaksinen 1979; Linsenmeyer 2014; McNicoll 2003; Muncie 1989; Waites 2006). These studies were assessed as unclear risk of bias. Group assignment was determined by a computer-generated list of random numbers, placed in opaque envelopes, which were opened 
by the participant after consent was obtained in Moore 2009 (low risk of bias).

\section{Blinding}

Most studies gave insufficient or no information relating to blinding. This may have been because blinding in this area of research is difficult; both participants and healthcare providers are aware of bladder washout being performed, and different washout solutions may look different and can be identified. There were no details about blinding of participants, healthcare providers or study assessors in relation to the intervention in four studies (Airaksinen 1979; Kennedy 1992; McNicoll 2003; Muncie 1989). These were assessed as unclear risk of bias. Moore 2009 acknowledged that it was not possible to blind the research nurse (who was also the outcome assessor who performed the washout) to the two washout solutions due to the nature of the packaging. Participants and healthcare providers in two studies were blinded to treatment status but descriptions were not provided (Linsenmeyer 2014; Waites 2006). These studies were assessed at low and unclear risk of bias, respectively.

\section{Incomplete outcome data}

All included trials reported significant rates of withdrawals and drop-outs, resulting in incomplete outcome data. However, withdrawals and drop-outs were well described generally with four trials assessed as low risk and three of unclear risk. Two trials (Muncie 1989; Waites 2006) explored differences between completers and non-completers. Two small trials (Kennedy 1992; McNicoll 2003) reported serious losses of participants resulting in few data for analysis (14 and 4 participants, respectively), compared with larger analysis data sets of other trials (Airaksinen $1979 \mathrm{~N}=36$, Linsenmeyer $2014 \mathrm{~N}=48$, Moore $2009 \mathrm{~N}=53$, Muncie $1989 \mathrm{~N}=32$, and Waites $2006 \mathrm{~N}=52$ ).

\section{Selective reporting}

Most trials reported all outcomes in results sections and were assessed as low risk. There was some discrepancy in outcomes reported in Airaksinen 1979 which was assessed as unclear risk of bias. McNicoll 2003 stated in the methods section that UTI rates were to be reported, but these were not described in the results. This trial was judged at high risk of bias.

\section{Other potential sources of bias}

Only Moore 2009 stated that data were analysed using an intentionto-treat analysis for the primary outcome variable; that is, the length of time each catheter was in situ was recorded as the date the participant withdrew from the study. The remaining trials either did not analyse according to the intention-to-treat principle (Linsenmeyer 2014; McNicoll 2003; Muncie 1989; Waites 2006) or this was unclear (Airaksinen 1979; Kennedy 1992).

\section{Effects of interventions}

See: Summary of findings for the main comparison Any washout compared to no washout for participants with long-term indwelling urinary catheterisation; Summary of findings 2 One washout solution versus another for participants with long-term indwelling urinary catheterisation

With two exceptions (Linsenmeyer 2014; McNicoll 2003), all included studies reported data on bacteriuria or symptomatic
UTI. All except two trials (Airaksinen 1979; Waites 2006) presented data on catheter removal rates, either reporting mean number of days a catheter was in situ (Kennedy 1992; Moore 2009) or mean number of replacements (McNicoll 2003; Muncie 1989). Kennedy 1992, Linsenmeyer 2014, and Moore 2009 looked specifically at the problem of catheter blockage due to encrustation. Four trials reported data on complications or adverse events of washouts: Kennedy 1992 reported red blood or urothelial cells in the washout fluid; Moore 2009 investigated incidence of microscopic haematuria and leukocytes in pre-washout dipstick urinalysis; Linsenmeyer 2014 looked at irrigation-induced autonomic dysreflexia; and Waites 2006 reported bladder spasms due to the washout procedure. Only McNicoll 2003 considered health economic outcomes, reporting on the cost and time of administration.

Some included trials addressed more than one pre-identified intervention comparison. Four trials provided data on washout versus no washout (Airaksinen 1979; McNicoll 2003; Moore 2009; Muncie 1989). Four trials compared different types of washout solutions (Kennedy 1992; Linsenmeyer 2014; Moore 2009; Waites 2006). Kennedy 1992 compared three washout solutions: saline with one acidic solution (Solution $\mathrm{R}$, contained $6 \%$ citric acid) with another alternative composition (Suby G, contained 3.23\% citric acid).

Insufficient data were available in a form that enabled entry for meta-analysis. No data were entered from four trials (Kennedy 1992; McNicoll 2003; Muncie 1989; Waites 2006). Kennedy 1992 and Muncie 1989 were cross-over trials which did not present data in a way that highlighted the paired nature of the data, making assessment problematic. Data from only four participants were reported in McNicoll 2003. In Waites 2006 and Linsenmeyer 2014 investigators reported combined outcome data for participants with urethral and suprapubic catheters which made clinicallyrelevant interpretation difficult.

The trials had small sample sizes (range 25 to 89), although numbers of participants who completed were far fewer (range 4 to 53). The authors of one of the largest trials (Moore 2009) ( $N=73 ; N$ $=53$ completed) proposed, based on their data, that a trial with at least 400 participants per arm would be required to give adequate power to detect a $20 \%$ difference in length of time each catheter was in situ.

\section{Any catheter washout versus no washout}

Four trials addressed this comparison (Airaksinen 1979; McNicoll 2003; Moore 2009; Muncie 1989).

\section{Symptomatic urinary tract infection (UTI)}

Moore 2009 reported no symptomatic UTIs in any study participants in the washout or non-washout groups (Analysis 1.1). Symptomatic UTI was defined by Moore 2009 as the presence of at least one of five indications: fever, urgency, dysuria or suprapubic tenderness, haematuria or positive urine culture. Self-reported UTIs (which did not meet the study criteria for symptomatic UTI) were noted in each group (citric acid 5/24, saline $2 / 18$, no washout $3 / 23$, P not reported).

\section{Number of catheters used}

No data were reported. 


\section{Length of time each catheter in situ}

Moore 2009 recorded the number of weeks until first catheter change and reported no significant differences in the mean time for the three groups: citric acid 4.57 (SD 2.61) $(\mathrm{N}=19)$; saline 5.18 (SD 2.90) $(\mathrm{N}=16)$; and no washout $4.55(\mathrm{SD} 2.91, \mathrm{~N}=20)(\mathrm{P}=0.642$; Analysis 1.2).

\section{Catheter removal rates due to blockage or infection}

The mean catheter replacement rate per 100 days of catheterisation was reported by Muncie 1989: for the saline washout periods the mean was 5.5 catheters replaced $(n=32)$, for the no washout periods the mean was 4.7 catheters replaced $(n=32)$. Muncie 1989 also reported (saline washout/no washout) numbers of catheters for each period: replaced due to obstruction (39/32); replaced due to leakage (11/21); and removed out with the study protocol $(87 / 63)$. The study authors concluded that daily saline washouts had no significant effect on the incidence of total number of catheter replacements. No details of statistical tests were presented.

McNicoll 2003 reported on the mean number of catheter replacements during a 12 week period: the citric acid washout group mean was 9 (SD 0$)(n=1)$, the no-washout group mean was 14.3 (SD 11.2, $\mathrm{n}=3$; P not reported).

Airaksinen 1979 also compared different types of silicone catheters. All participants received new catheters on day 0; participants in both Silicath catheter groups had these replaced at three months (as per manufacturers' guidelines). Airaksinen 1979 stated that in the Silicath catheter group with regular irrigation, 5/10 participants required a catheter change in the first three months of the study compared to those with similar catheters who were in the control group (no irrigation) in which $8 / 10$ participants required a catheter change (Analysis 1.3 ; stated $P<0.01$ ). In the silastic catheter intervention group 2/11 participants required a catheter change compared with 2/9 participants in the silastic control group (Analysis 1.3; RR $0.67,95 \% \mathrm{Cl} 0.34$ to $1.31, \mathrm{P}<0.50 ; 1$ study. 40 participants; very low quality evidence).

\section{Rates of asymptomatic bacteriuria}

Given that catheter obstructions may be related to particular bacterial species, Muncie 1989 reported the mean number of species at $\geq 10^{5} \mathrm{CFU} / \mathrm{mL}$ per urine specimen for each group ( $\mathrm{N}=23$ participants) who completed the cross-over trial. Urine specimens were obtained for culture every two weeks. For the saline washout periods the mean was 4.0 , for the no washout periods the mean was 3.8. No test of statistical difference was reported. The four most prevalent organisms were Providencia stuartii, Escherichia coli, $P$ mirabilis and Enterococcus spp. The percentage of specimens in which each strain was present was similar in the saline washout and no washout periods of the study.

\section{Washout acceptability measures}

No data were reported.

\section{Health status or measures of psychological health}

No data were reported.

\section{Complications and adverse events}

Muncie 1989 looked at episodes of high temperature with possible urinary origin as a proxy for symptomatic UTI. Data were reported for 32 participants (including those who did not complete the trial) for combined phases of this cross-over trial. The mean number of episodes of high temperature of possible urinary origin per 100 days of catheterisation for the three periods was reported: mean for the saline washout period was 1.2 (SD 1.3), and for the no washout period was 0.9 (SD 1.1). This was also reported separately for each period of the study: period 1 , irrigation versus none; period 2 , irrigation versus none; and for all episodes of high temperature (Analysis 1.4) as well as those of urinary origin (Analysis 1.5). The study authors reported that the difference was not statistically significant, although no details were given.

\section{Health economic outcomes}

McNicoll 2003 reported that 37.25 hours were spent administering washouts over the 12 week period for one participant in the intervention group. McNicoll 2003 reported that care for the "planned catheter change" group took less time, but no comparison data were presented. The cost of the intervention was GBP 975.51 for the participant in the washout group whose treatment required over 37 hours of washout time compared to a mean GBP 189 (SD GBP 103) per person for the cost of care in the control group. The price per year was not given.

\section{One type of catheter washout solution versus another}

Four trials addressed this comparison (Kennedy 1992; Linsenmeyer 2014; Moore 2009; Waites 2006).

\section{Symptomatic UTI}

The rate of participants discontinuing the use of washouts due to the development of a symptomatic UTI was reported by Waites 2006: saline $1 / 29$ participants (3\%), acetic acid $6 / 30$ participants (20\%), and neomycin-polymyxin $4 / 30$ participants (13\%). The difference between groups was not statistically significant $(P=$ $0.15)$. Overall, a significantly greater proportion of acetic acid group participants discontinued $(P=0.0005)$, but this difference was due to more participants in this group discontinuing for "personal reasons unrelated to health". Moore 2009 found no symptomatic UTIs in any group in the trial using the citric acid or saline solutions (Analysis 2.1).

\section{Number of catheters used}

No data were reported.

\section{Length of time each catheter in situ}

Kennedy 1992 reported mean days the catheter was in situ: saline 16.3 days, Suby G 14.3 days, Solution R 14.2 days. No standard deviations were reported, but the study authors reported no significant differences between groups ( $P$ not reported). It was noted that only three participants retained their catheter for the full length of each trial period. Moore 2009 reported the mean time until first catheter change; there was no significant difference among trial groups, including the two groups receiving different washout solutions (citric acid versus saline, Analysis 2.2). 


\section{Catheter removal rates due to blockage or infection}

In Kennedy 1992, 100 of 120 study catheters were examined for encrustation. The number of catheters found to be blocked (defined as the eye or lumen completely blocked resulting in no flow of urine) when removed after each three week solution period was reported: saline $18 / 44$ catheters (41\%), Suby G $14 / 29$ catheters (48\%), Solution R $7 / 27$ catheters $(26 \%)$. The study authors concluded that Solution R produced the best results and Suby $G$ the worst, but no statistical tests were presented, and a time effect was noted such that blocked catheters would be removed early (before they could be examined) thus distorting the data. Regarding degree of visual encrustation, Kennedy 1992 reported little difference among the three solutions up to day 10, after which it was felt Solution $\mathrm{R}$ did not reduce encrustation. Mean encrustation scores were presented but without standard deviations. Similarly, insufficient information was presented relating to the mean number of episodes of bypassing per week (saline 1.55, Suby $G$ 1.4, Solution R 1.9), although the study authors reported that differences among groups for this outcome were not statistically significant ( $P$ value not reported).

Linsenmeyer 2014 compared auriclosene and saline washouts and reported encrustation rates only for participants in this study $(\mathrm{N}=$ 14). The area of encrustation (expressed as a percentage) within the catheter was assessed at three pre-selected locations. The maximum encrustation in any part of the catheter was used to determine catheter patency and was the primary endpoint of this trial. The auriclosene irrigation resulted in an average encrustation of $21.7 \%$ ( $95 \% \mathrm{Cl} 2.1 \%$ to $41.2 \%$ ), versus $76.9 \%$ (95\% Cl $54.9 \%$ to $98.8 \%)$ average encrustation with saline ( $\mathrm{P}$ value not reported). Linsenmeyer 2014 reported percentages of catheters removed for clinical blockage and due to $100 \%$ encrustation. Of those irrigated with the auriclosene solution, $14 \%$ had to be removed due to any clinical blockage; none of these catheters were $100 \%$ encrusted. By contrast, $64 \%$ of catheters irrigated with saline were removed due to clinical blockage, and of these, all were completely blocked.

\section{Rates of asymptomatic bacteriuria}

In the cross-over trial by Kennedy 1992 comparing three solutions, the percentage of participants with bacteria observed in washout fluid at the end of a washout period with one of the trial solutions were: saline $100 \%$, Suby G $75 \%$, Solution R $76 \%$. Only percentages were presented and the denominators were unclear for these percentages. The presence of bacteria was also measured in 66 urine specimens collected from 25 participants at the time of catheter change. Of these, four samples showed no significant bacterial growth ( 3 after antibiotic treatment and 1 after saline washouts). It was therefore concluded that none of the solutions tested eliminated bacteria. The study authors stated that Suby $\mathrm{G}$ and Solution $\mathrm{R}$ appeared to reduce levels of bacteria but that differences were not statistically significant (statistical test results were not presented). It was further concluded that treatment with acidic solutions (Suby $\mathrm{G}$ and Solution $\mathrm{R}$ ) did not prevent or reduce urease-producer bacteria. The published data on presence of bacteria were inadequately reported.

The percentages of participants harbouring Enterococcus spp (alone or in conjunction with other types of bacteria) after completing the Waites 2006 trial were: saline 13/21 participants $(62 \%)$, acetic acid $7 / 9$ participants $(87 \%)$ and neomycin-polymyxin $19 / 22$ participants $(86 \%)$. No test of significant difference between groups was presented. In the antibiotic group, from study start to finish there was a significant increase in the number of participants with Enterococci spp bacteria $(P=0.02)$. Data were reported graphically; exact values were not available. The study authors reported detecting no advantages from the antibiotic or acidic solutions over saline in reducing urinary bacterial load.

\section{Washout acceptability measures}

No data were reported.

\section{Health status or measures of psychological health}

No data were reported.

\section{Measures of complications or adverse effects}

\section{Blood in the urine}

The presence of blood in the urine may indicate damage caused by the washout procedure. Kennedy 1992 reported the percentage of participants in each group who had red blood cells in their washout fluid at the end of each treatment period (saline $21 \%$, Suby G $17 \%$, Solution R $14 \%)$. Study authors also reported a significant difference among treatment groups $(P=0.028)$ associated with a higher red blood cell count in the Suby $\mathrm{G}$ group compared to other groups. Moore 2009 reported results from urine dipstick testing, and found that all participants, irrespective of group, exhibited blood in the urine consistently.

\section{Urothelial cells in the urine}

Presence of urothelial cells in washout fluid at the end of each treatment period was reported by Kennedy 1992: saline 100\%, Suby G $86 \%$, Solution R $100 \%$. Study authors reported finding evidence of a significant difference among treatment groups for urothelial cells over time $(P=0.068)$, but that this was unlikely to be clinically significant.

\section{Bladder spasms}

Waites 2006 reported on the incidence of bladder spasms directly attributable to bladder washout, which occurred on a small number of occasions (saline $0 / 29$ participants, acetic acid $1 / 30$ participants, neomycin-polymyxin 2/30 participants). Bladder spasms caused these participants to discontinue with washouts (P not reported).

\section{Health economic outcomes}

No data were reported.

\section{Clinically or microbiologically indicated washout versus routine washout}

No data were reported.

\section{Long intervals between catheter washouts versus short intervals}

No data were reported.

\section{One method of administration of catheter washouts versus another method}

No data were reported.

\section{Smaller volumes of washout solution versus larger volumes}

No data were reported. 


\section{A stronger solution of washout versus a weaker solution}

Kennedy 1992 addressed this comparison in a cross-over trial. Kennedy 1992 compared two acidic solutions with different compositions. The citric acid content of one solution (solution $\mathrm{R}, 6 \%$ ) was higher than the other (Suby G, 3.23\%), however it was noted that the other elements of the solutions also differed. Therefore, any differences may not be attributable to the strength of the citric acid solution.

\section{Symptomatic UTI}

No data were reported.

\section{Number of catheters used}

No data were reported.

\section{Length of time each catheter in situ}

The mean time for catheter in situ was 14.3 days (Suby G) and 14.2 days (Solution R). No significant differences were found (Kennedy 1992).

\section{Catheter removal rates due to blockage or infection}

The study authors concluded that Solution R performed better than Suby $\mathrm{G}$ in terms of fewer blocked catheters ( $26 \%$ versus $48 \%$, no significance test reported). The results presented did not utilise the cross-over nature of the trial and were not informative (Kennedy 1992).

\section{Rates of asymptomatic bacteriuria}

Kennedy 1992 concluded there was no significant difference ( $P$ not reported) between Suby $G$ (containing 3.23\% citric acid) and Solution $\mathrm{R}$ (containing $6 \%$ citric acid) in terms of reducing the level of bacteria in the urine.

\section{Washout acceptability measures}

No data were reported.

\section{Health status or measures of psychological health}

No data were reported.

\section{Measures of complications or adverse effects}

No data were reported.

\section{Health economic outcomes}

No data were reported.

\section{A single washout instillation versus two or more sequential washout instillations of the same type}

No data were reported.

\section{DISCUSSION}

There were insufficient data providing reliable evidence about the benefit or harms of washout policies to prevent catheter blockage or encrustation or for the relative merits of different washout solutions. Given that it was not possible to obtain sufficient information for further interpretation or analysis of existing published data from study authors, further high quality trials must be considered to provide rigorous evidence relating to the use of washouts. There are several important issues raised by this review which have implications for future research in this area.

\section{Summary of main results}

We identified seven trials eligible for inclusion in this review relating to the use of washouts for people with long-term indwelling catheters. Most trials were small and under powered with inadequate reporting to permit judgement. The studies reviewed consisted of three randomised cross-over trials which had poor data reporting, three parallel group randomised controlled trials (RCTs) with very limited data, and one well-designed, but potentially under-powered, RCT. Of the nine primary and secondary outcome measures sought, data were available for six. Trials assessed only three of the eight intervention comparisons identified. Due to the imprecision of the results of the included trials we are uncertain if washouts have an important effect on the primary outcomes of numbers of participants with symptomatic urinary tract infections (UTIS) and length of time each catheter was in situ. Main results are summarised in Summary of findings for the main comparison and Summary of findings 2 .

\section{Overall completeness and applicability of evidence}

None of the included trials addressed: number of catheters used, washout acceptability measures (including patient satisfaction, patient discomfort, pain and ease of use), or health status/ measures of psychological health and very limited health economic data were available. Any new policy regarding the management of long-term urinary catheters with or without the use of washout solutions must be shown to be favourable for these important outcomes. As for the eight pre-identified washout comparisons, the included trials provided data relating to only three (any catheter washout solution versus no catheter washout; one type of catheter washout solution versus another type; and a stronger washout solution versus a weaker washout solution). No trials looked at different volumes of the same washout solution. Studies tended to use the volume of solution provided in the manufacturer's preprepared containers. Volumes ranged from $10 \mathrm{~mL}$ (Airaksinen 1979) to $100 \mathrm{~mL}$ (Kennedy 1992). None of the trials compared different washout frequencies. However, washout frequency varied: twice daily (Waites 2006), daily (McNicoll 2003; Muncie 1989), twice weekly (Linsenmeyer 2014; Waites 2006), weekly (Moore 2009), and every two weeks (Airaksinen 1979). The length of time the washout was retained in the bladder ranged from 15 minutes (Linsenmeyer 2014; Moore 2009) to 20 to 30 minutes (Kennedy 1992)), as did the duration of the intervention from 3 weeks (Kennedy 1992) to 26 weeks (Airaksinen 1979).

It is important that a washout period is used in cross-over trials where there is potential for a carry-over effect from one treatment period to the next. Both included cross-over trials used this approach; Muncie 1989 used a two-week phase between trial periods with no intervention, and Kennedy 1992 used a oneweek phase during which participants had a saline washout. Both Muncie 1989 and Kennedy 1992 also used run-in periods of two weeks of no washout and one week of saline washout respectively. Linsenmeyer 2014 stated that a washout period was used between different solutions but the timing was not provided. No reason was given for length of the run-in or washout periods.

Included trials' participants varied in several ways. In some trials participants had histories of blocked catheters (Linsenmeyer 2014; 
McNicoll 2003; Moore 2009); other trials did not limit participation in this way, or did not mention any history of catheter blocking. There may be merit in looking specifically at those people with a history of catheter blocking; anecdotally, it is thought that some people are more susceptible than others.

The participant characteristics and settings varied in the trials. Kennedy 1992 and Muncie 1989 studied older women (mean ages 82 years and 71 years, respectively) who were inpatients in longterm or geriatric care settings compared to community-dwelling men and women with neurogenic bladder studied by Waites 2006 (mean age 45.8 years) and Linsenmeyer 2014 (mean age 46.6 years). Moore 2009 and Airaksinen 1979 studied a mix of long-term or hospital care and home care participants. No information on age and gender was available for McNicoll 2003. The effects of a washout, if any, may differ in such diverse populations and careful thought is needed regarding whether such trials results could be usefully compared in future reviews.

\section{Quality of the evidence}

The quality of the trials and their reporting was generally inadequate. All the trials had small sample sizes; overall 349 participants were randomised and 217 completed the studies. The randomisation sequence of participants was clearly described in only two trials (Kennedy 1992; Moore 2009) and unclear in five. Concealment of group allocation was poor or inadequately described in all but one trial (Moore 2009). Three trials were deemed at high risk of bias for lack of blinding (McNicoll 2003; Moore 2009; Muncie 1989). However, depending on the washout regimen, blinding of participants or the health professional to the intervention may have been impossible. In regard to detection bias, the seven studies did not describe accurately the methods of detecting outcomes; therefore, all were assessed as unclear risk of bias. We assessed four trials (Kennedy 1992; Moore 2009; Muncie 1989; Waites 2006) to be at low risk of attrition bias. Three lacked detail and were judged to be an unclear bias (Airaksinen 1979; Linsenmeyer 2014; McNicoll 2003).

The included trials were somewhat heterogeneous in terms of the outcomes measured. Most trials assessed bacteriuria, and blockage/encrustation, although methods for doing so and definitions used varied greatly. Definitions of symptomatic UTI in particular were poorly described and differed among trials. Standardised methods for assessing these key outcomes in catheter research are needed. There was a consistent lack of adequate reporting of statistical information e.g. denominators for percentages, summary statistics such as standard deviations and details of statistical tests. This made interpreting the study results difficult, and extracting the data impossible in many cases. The methods used by study authors to analyse data from the cross-over trials were referenced and seemed appropriate, taking into account the paired nature of the data. However, the reporting of these analyses in the reports was poor and assessment of the findings and data extraction were not possible.

\section{Potential biases in the review process}

We searched all relevant databases without language restriction to obtain as many reports of trials as possible. We also included trial registries in this search and contacted authors for further information about trials that were reported as completed, where applicable. However, despite these attempts to minimise publication bias it is possible that not all eligible trials were included in the databases that we searched. To reduce the risk of bias during the review process, we used the methodology described in the Cochrane Handbook for Systematic Reviews of Interventions (Higgins 2011), this included two authors screening the literature search results for potentially eligible studies and double data extraction.

\section{Agreements and disagreements with other studies or reviews}

The Centers for Disease Control and Prevention (CDC) Guideline for prevention of catheter-associated urinary tract infections (CAUTI) was updated in 2009 due to an increasing focus on the non-acute setting and patients in need of long-term urinary catheterisation. The Guideline considered the best practices for preventing CAUTI associated with obstructed urinary catheters and concluded that no recommendation could be given for the use of irrigation solutions because the evidence was not available to answer the question. Many of the studies referred to by Gould 2010 considered patients who used intermittent catheterisation and therefore were not included in this review because they did not match our inclusion criteria. The findings of Gould 2010 agree with findings from this review and provide further support for the need for high quality trials in this area. No other systematic reviews of catheter washout solutions were found.

\section{AUTHORS' CONCLUSIONS}

\section{Implications for practice}

There is currently insufficient evidence from randomised controlled trials (RCTs) to guide clinical practice regarding all aspects of using washouts for long-term indwelling catheters. It is unknown if washouts convey any benefits or harms for patients using indwelling catheters in the long-term. We found very little evidence on economic outcomes associated with managing long-term indwelling catheter use.

\section{Implications for research}

There is a need for a large RCT with rigorous methods which will determine the optimal policies to prevent or relieve catheter blockage. This trial would initially include a 'no washout' arm as there is first a need for evidence regarding whether catheter washouts compared to no washout are beneficial. Objective measures of catheter-associated urinary tract infection (CAUTI) and blockage including length of time catheter in situ, catheter removal rates, and number of catheters used would be key outcome measures. Washout acceptability (patient discomfort, satisfaction, pain), and psychological health (quality of life) using validated tools must also be considered. Health economic analysis associated with different washout regimens must also be reported. Other variables that may influence outcome, and which should be allowed for in the design of a future trial, include baseline characteristics of urine (e.g. acidity), condition of patient dictating the need for indwelling catheterisation, and the patient's fluid intake. We would also suggest that long-term follow up is needed; this would provide very valuable evidence. Given the difficulty experienced in previous trials in recruiting and retaining participants, it may be sensible to standardise the different types of catheters in future trials to maximise the chances of detecting any differences between groups. 
With one exception (Waites 2006), the washout procedure was undertaken by a healthcare professional in the included studies. After the first washout Waites 2006 gave pre-prepared solutions to the participant to use at home. This is an interesting, and potentially cost-saving, approach to catheter care which may be appropriate for certain patient groups, and could perhaps be the subject of a future trial.

Most trials assessed bacteriuria, symptomatic urinary tract infections (UTIS) and blockage/encrustation, although methods for doing so and definitions used varied. Standardised methods for assessing these key outcomes in catheter research are needed. There was a consistent lack of adequate reporting of statistical information e.g. denominators for percentages, summary statistics such as standard deviations and details of statistical tests. This made interpreting the study results difficult, and extracting the data impossible in many cases. The methods used by study authors to analyse data from the cross-over trials were referenced and seemed appropriate, taking into account the paired nature of the data. However, the reporting of these analyses in the reports was poor and assessment of the findings and data extraction were not possible.

\section{ACKNOWLEDGEMENTS}

The review authors would like to thank Sheila Wallace of the Cochrane Incontinence Group for her assistance with searching and developing the search strategy. The authors would wish to thank both Lesley Sinclair and Stephen Cross who were co-authors of the original review (Hagen 2010). 


\section{R E F E R E N C E S}

\section{References to studies included in this review}

Airaksinen 1979 \{published data only\}

Airaksinen P, Sinkkonen S, Bolodin M, Jauhiainen R. A clinical study on patients with indwelling catheters [Kestokatetrihoiden Kliininen Tutkimus]. Duodecim 1979;95(4):164-70.

\section{Kennedy 1992 \{published data only\}}

Kennedy AP, Brocklehurst JC, Robinson JM, Faragher EB. Assessment of the use of bladder washouts/instillations in patients with long-term indwelling catheters. British Journal of Urology 1992;70(6):610-5. [sr-incont1356]

\section{Linsenmeyer 2014 \{published data only\}}

* Linsenmeyer T, Goetz L, Kennelly M, Najafi RR, Costerton W, Stickler D, et al. Auriclosene irrigation solution reduces indwelling urinary catheter encrustation and prevents blockage: Results of a phase 2 clinical study (Abstract number PD37-10). Journal of Urology 2014;191(4 Suppl 1):e949. [srincont67145]

NCT01243125, Krantz KD. Study to evaluate NVC-422 for urinary catheter blockage and encrustation. https:/clinicaltrials.gov/ ct2/show/NCT01243125 (accessed 15 June 2016). [srincont60016

\section{McNicoll 2003 \{published data only\}}

McNicoll D. Encrusted urinary catheters: how should nurses manage them?. Journal of Community Nursing 2003;17(12):10-4.

\section{Moore 2009 \{published data only\}}

Moore KN, Hunter KF, McGinnis R, Bacsu C, Fader M, Getliffe K, et al. Do catheter washouts extend patency time in long term urethral catheters? A randomized controlled trial of acidic washout solution, normal saline washout, or standard care. Journal of Wound Ostomy and Continence Nursing 2009;36(1):82-90.

\section{Muncie 1989 \{published data only\}}

Muncie HL Jr, Hoopes JM, Damron DJ, Tenney JH, Warren JW. Once-daily irrigation of long-term urethral catheters with normal saline. Lack of benefit. Archives of Internal Medicine 1989;149(2):441-3

\section{Waites 2006 \{published data only\}}

Waites KB, Canupp KC, Roper JF, Camp SM, Chen Y. Evaluation of 3 methods of bladder irrigation to treat bacteriuria in persons with neurogenic bladder. Journal of Spinal Cord Medicine 2006;29(3):217-26

\section{References to studies excluded from this review}

\section{Andersson 1986 \{published data only\}}

Andersson $\mathrm{H}$. A double-blind randomized comparison of the effect and tolerance of Varidase versus saline when instilled in the urinary bladder in patients with catheter problems. Journal of International Medical Research 1986;14(2):91-4. [ISSN 0300-0605 (Print)]
Bach 1990 \{published data only\}

Bach D, Hesse A, Prange $\mathrm{CH}$. Prevention of incrustations and urinary tract infections during transurethral continuous catheterization [Inkrustations- und Harnwegsinfekt- prophylaxe beim transurethralen Dauerkatheter]. TW Urologie Nephrologie 1990;2(1):25-32. [ISSN 0936-2002]

Bruun 1978 \{published data only\}

Bruun JN, Digranes A. Bladder irrigation in patients with indwelling catheters. Scandinavian Journal of Infectious Diseases 1978;10(1):71-4.

Davies 1987 \{published data only\}

Davies AJ, Desai HN, Turton S, Dyas A. Does instillation of chlorhexidine into the bladder of catheterized patients help reduce bacteriuria?. Journal of Hospital Infection 1987;9(1):72-5. [ISSN 0195-6701 (Print)]

Elliott 1989 \{published data only\}

Elliott TSJ, Reid L, Gopal Rao G, Rigby RC, Woodhouse K. Bladder irrigation or irritation?. British Journal of Urology 1989;64(4):391-4. [ISSN 0007-1331]

Elliott 1990 \{published data only\}

Elliott TS. Disadvantages of bladder irrigation. Nursing Times 1990;86(4):52.

\section{Furuno 1998 \{published data only\}}

Furuno T. Usefulness of bladder irrigation with super oxidation water (Abstract). Japan Medical Society of Paraplegia. 1998; Vol. 12, issue 1:244-5. [ISSN 0914-6822]

Gelman 1980 \{published data only\}

Gelman ML. Antibiotic irrigation and catheter-associated urinary tract infections. Nephron 1980;25(5):259.

\section{Kennedy 1984 \{published data only\}}

Kennedy A. Trial of a new bladder washout system. Nursing Times 1984;80(46):48-51. [MEDLINE: 2583]

\section{Meyers 1964 \{published data only\}}

Meyers MS, Schroeder BC, Martin CM. Controlled trial of nitrofurazone and neomycin-polymyxin as constant bladder rinses for prevention of post indwelling catheterisation bacteriuria. Antimicrobial Agents and Chemotherapy 1964;8:571-81.

Robertson 1990 \{published data only\}

Robertson MH, Norton MS. Effect of $1 \%$ mandelic acid as a bladder irrigation fluid in patients with in-dwelling catheters. British Journal of Clinical Practice 1990;44(4):142-4.

Ruwaldt 1983 \{published data only\}

Ruwaldt MM. Irrigation of indwelling urinary catheters. Urology 1983:21(2):127-9.

Vainrub 1977 \{published data only\}

Vainrub B, Musher DM. Lack of effect of methenamine in suppression of, or prophylaxis against, chronic urinary 
infection. Antimicrobial Agents and Chemotherapy 1977;12(5):625-9. [ISSN 0066-4804]

Warren 1978 \{published data only\}

Warren JW, Platt R, Thomas RJ, Rosner B, Kass EH. Antibiotic irrigation and catheter-associated urinary-tract infections. New England Journal of Medicine 1978;299(11):570-3. [MEDLINE: 1068]

\section{References to ongoing studies}

NCT02130518 \{published data only\}

NCT02130518, Krantz KD, lovino SM. Efficacy study of auriclosene irrigation solution on urinary catheter patency [A multicenter, randomized, double-blind, three-arm efficacy study of auriclosene irrigation solution on indwelling urinary catheter patency]. https://clinicaltrials.gov/show/NCT02130518 2014 (accessed 15 June 2016) (first received 1 May 2014). [srincont60927]

\section{Additional references}

\section{Atkins 2004}

Atkins D, Best D, Briss PA, Eccles M, Falck-Ytter Y, Flottorp S, and GRADE Working Group. Grading quality of evidence and strength of recommendations. BMJ 2004;328(7454):1490-7.

\section{Bibby 1993}

Bibby JM, Hukins DW. Acidification of urine is not a feasible method for preventing encrustation of indwelling urinary catheters. Scandinavian Journal of Urology and Nephrology 1993;27(1):63-5.

\section{Capewell 1993}

Capewell AE, Morris SL. Audit of catheter management provided by district nurses and continence advisors. British Journal of Urology 1993;71(3):259-64.

\section{ECDC 2014}

European Centre for Disease Prevention and Control (ECDC). Surveillance report. Point prevalence survey of healthcareassociated infections and antimicrobial use in European longterm care facilities. April-May 2013. http://ecdc.europa.eu/en/ publications/_layouts/forms/Publication_DispForm.aspx? List=4f55ad51-4aed-4d32-b960-af70113dbb90\&ID=1087 2014 (accessed 15 June 2016). [DOI: 10.2900/24172; ISBN 978-92-9193-571-0]

\section{Evans 2000}

Evans A, Pheby D, Painter D, Feneley R. The costs of long-term catheterization in the community. British Journal of Community Nursing 2000;5(10):477-88.

\section{Garibaldi 1974}

Garibaldi RA, Burke JP, Dickman ML, Smith CB. Factors predisposing to bacteriuria during indwelling urethral catheterization. New England Journal of Medicine 1974;291(5):215-9.

\section{Getliffe 1992}

Getliffe KA. Encrustation of urinary catheters in community patients [PhD thesis]. Guildford (UK): University of Surrey, 1992.

\section{Getliffe 1994}

Getliffe KA. The use of bladder wash-outs to reduce urinary catheter encrustation. British Journal of Urology 1994;73(6):696-700. [MEDLINE: 94306075]

\section{Getliffe 1996}

Getliffe KA. Bladder instillations and bladder washouts in the management of catheterized patients. Journal of Advanced Nursing 1996;23(3):548-54.

\section{Getliffe 2003}

Getliffe K. Managing recurrent urinary catheter blockage: problems, promises, and practicalities. Journal of Wound, Ostomy, and Continence Nursing 2003;30(3):146-51.

\section{Getliffe 2006}

Getliffe K, Newton T. Catheter-associated urinary tract infection in primary and community health care. Age and Ageing 2006;35(5):477-81.

\section{Gould 2010}

Gould CV, Umscheid CA, Agarwal RK, Kuntz GK, Pegues DA: Healthcare Infection Control Practices Advisory Committee. Guideline for prevention of catheter-associated urinary tract infections 2009. Infection control and Hospital Epidemiology 2010;31(4):319-26.

\section{GRADEpro GDT 2015 [Computer program]}

McMaster University (developed by Evidence Prime Inc). GRADEpro GDT. Hamilton (ON), Canada: GRADE Working Group, McMaster University, 2015. Available at: http://gradepro.org (accessed 31 January 2017).

\section{Hamory 1978}

Hamory BH, Wenzel RP. Hospital-associated candiduria: predisposing factors and review of the literature. Journal of Urology 1978;120(4):444-8.

\section{Hesse 1989}

Hesse A, Schreyger F, Tuschewitzki GJ, Classen A, Bach D. Experimental investigations on dissolution of incrustations on the surface of catheters. Urologia Internationalis 1989;44(6):364-9.

\section{Hesse 1992}

Hesse A, Nolde A, Klump B, Marklein G, Tuschewitzki GJ. In vitro investigations into the formation and dissolution of infectioninduced catheter encrustations. British Journal of Urology 1992;70(4):429-34.

\section{Higgins 2011}

Higgins JPT, Green S (editors). Cochrane Handbook for Systematic Reviews of Interventions Version 5.1.0 [updated March 2011]. The Cochrane Collaboration, 2011. Available from www.cochrane-handbook.org. 


\section{HIS 2004}

Healthcare Improvement Scotland. Urinary catheterisation and catheter care. Best practice statement. www.healthcareimprovementscotland.org/previous_ resources/best_practice_statement/urinary_catheterisation_care.aspx June 2004 (accessed prior to 9 February 2017).

\section{King 1991}

King JB, Stickler DJ. An assessment of antiseptic bladder washout solutions using a physical model of the catheterized bladder. Journal of Hospital Infection 1991;18(3):179-90. [MEDLINE: 92012952]

\section{Kohler-Ockmore 1996}

Kohler-Ockmore J, Feneley RCL. Long-term catheterization of the bladder: prevalence and morbidity. British Journal of Urology 1996;77(3):347-51.

\section{Kunin 1987}

Kunin CM, Chin QF, Chambers S. Indwelling urinary catheters in the elderly. Relation of "catheter life" to formation of encrustations in patients with and without blocked catheters. American Journal of Medicine 1987;82(3):405-11.

\section{Padawer 2015}

Padawer D, Pastukh N, Nitzan O, Labay K, Aharon I, Brodsky D, et al. Catheter-associated candiduria: Risk factors, medical interventions, and antifungal susceptibility. American Journal of Infection Control 2015;43(7):e19-22.

\section{Pellowe 2003}

Pellowe CM, Pratt RJ, Harper P, Loveday HP, Robinson N, Jones SR, et al. Evidence-based guidelines for preventing healthcare-associated infections in primary and community care in England. Journal of Hospital Infection 2003;55(Suppl 2):S2-127.

\section{Pomfret 2004}

Pomfret I, Bayait F, Mackenzie R, Wells M, Winder A. Using bladder instillations to manage indwelling catheters. British Journal of Nursing 2004;13(5):261-7.

\section{Reference Manager 2012 [Computer program]}

Thomson Reuters. Reference Manager Professional Edition Version 12. New York: Thomson Reuters, 2012.

\section{RevMan 2014 [Computer program]}

Nordic Cochrane Centre, The Cochrane Collaboration. Review Manager 5 (RevMan 5). Version 5.3. Copenhagen: Nordic Cochrane Centre, The Cochrane Collaboration, 2014.

\section{Roe 1987}

Roe BH, Brocklehurst JC. Study of patients with indwelling catheters. Journal of Advanced Nursing 1987;12(6):713-8.

\section{Saint 1999}

Saint S, Lipsky BA. Preventing catheter-related bacteriuria: should we? Can we? How?. Archives of Internal Medicine 1999;159(8):800-8.

\section{SIGN 2012}

Scottish Intercollegiate Guidelines Network (SIGN). Management of suspected bacterial urinary tract infection in adults: a national clinical guideline. www.sign.ac.uk/guidelines/ fulltext/88/. Edinburgh: SIGN, Healthcare Improvement Scotland, 2012 (updated edition published July 2012) (accessed 15 June 2016). [ISBN 978190581388 9]

\section{Stark 1984}

Stark RP, Maki DG. Bacteriuria in the catheterized patient. What quantitative level of bacteriuria is relevant?. New England Journal of Medicine 1984;311(9):560-4.

\section{Stickler 2010}

Stickler DJ, Feneley RCL. The encrustation and blockage of longterm indwelling bladder catheters: a way forward in prevention and control. Spinal Cord 2010;48(11):784-90.

\section{Sørbye 2005}

Sørbye LW, Finne-Soveri H, Ljunggren G, Topinková E, Bernabei R. Indwelling catheter use in home care: elderly, aged 65+, in 11 different countries in Europe. Age and Ageing 2005;34(4):377-81.

\section{Ware 1993}

Ware JE. Measuring patients' views: the optimum outcome measure. SF-36: a valid, reliable assessment of health from the patient's point of view. British Medical Journal 1993;306(6890):1429-30.

\section{Wilks 2015}

Wilks SA, Fader MJ, Keevil CW. Novel insights into the Proteus mirabilis crystalline biofilm using real-time imaging. PloS One 2015;10(10):e0141711.

\section{Zigmond 1983}

Zigmond AS, Snaith RP. The hospital anxiety and depression scale. Acta Psychiatrica Scandinavica 1983;67(6):361-70.

\section{References to other published versions of this review Hagen 2010}

Hagen S, Sinclair L, Cross S. Washout policies in long-term indwelling urinary catheterisation in adults. Cochrane Database of Systematic Reviews 2010, Issue 3. [DOI: 10.1002/14651858.CD004012.pub4]

\section{Sinclair 2006}

Sinclair L, Cross S, Hagen S, Niël-Weise BS. Washout policies for the management of long-term indwelling urinary catheterisation in adults. Cochrane Database of Systematic Reviews 2006, Issue 1. [DOI: 10.1002/14651858.CD004012.pub3]

* Indicates the major publication for the study 
CHARACTERISTICS OF STUDIES

Characteristics of included studies [ordered by study ID]

Airaksinen 1979

Methods Study design: RCT with 4 groups. The study set out to compare a washout with saline versus no washout and also different types of silicone catheters (Silicath and Silastic)

Study duration: Six months

Participants Inclusion criteria: The inclusion criteria stated that participants required a long-term indwelling catheter for a minimum of six months.

Setting: Hospital and home care

Country: Finland

Health status: Participants were in good general health

Number: treatment $(N=20)$; control $(N=20)$

Age: Participants age range from 50 to 59 years up to 85 to 99 years

- Treatment: Ages in groups (number of trials): 50 years to 59 years (2), 60 years to 69 years (3), 70 years to 74 years (2), 75 years to 79 years (3), 80 years to 84 years ( 7 ), 85 years to 99 years (3)

- Control: Ages in groups (number of trials): 50 years to 59 years (1), 60 years to 69 years (2), 70 years to 74 years (6), 75 years to 79 years (5), 80 years to 84 years (3), 85 years to 99 years (3)

Sex: $(m / f): 16 / 24$

Exclusion criteria: Patients not in good general health or unlikely to survive the investigation period were excluded

Interventions

\section{Treatment group 1}

- Intervention: Saline washout

- Dose, duration, frequency, administration: Every two weeks, $10 \mathrm{~mL}$ or $20 \mathrm{~mL}$

- Other relevant information: Silicath catheter

\section{Treatment group 2}

- Intervention: Saline washout

- Dose, duration, frequency, administration: Every two weeks, $10 \mathrm{~mL}$ or $20 \mathrm{~mL}$

- Other relevant information: Silastic catheter

\section{Control group 1}

- Intervention: No washout

- Dose, duration, frequency, administration: Not applicable

- Other relevant information: Silicath catheter

\section{Control group 2}

- Intervention: No washout

- Dose, duration, frequency, administration: Not applicable

- Other relevant information: Silastic catheter

$\begin{array}{ll}\text { Outcomes } & \text { - Bacteriuria rates } \\ \text { - Symptomatic UTI rates } \\ \text { - Visual encrustation rates } \\ \text { - Rate of catheter obstruction/blockage }\end{array}$


Airaksinen 1979 (Continued)

How outcomes were measured: Not provided in translated copy

Notes Funding source: Not stated

Study written in Finnish and translated to English

\section{Risk of bias}

\begin{tabular}{|c|c|c|}
\hline Bias & Authors' judgement & Support for judgement \\
\hline $\begin{array}{l}\text { Random sequence genera- } \\
\text { tion (selection bias) }\end{array}$ & Unclear risk & Stated random allocation but no description given \\
\hline $\begin{array}{l}\text { Allocation concealment } \\
\text { (selection bias) }\end{array}$ & Unclear risk & $\begin{array}{l}\text { Stated that } 10 \text { participants allocated to each of the } 4 \text { groups but no further de- } \\
\text { tails provided }\end{array}$ \\
\hline $\begin{array}{l}\text { Blinding of participants } \\
\text { and personnel (perfor- } \\
\text { mance bias) } \\
\text { All outcomes }\end{array}$ & Unclear risk & No mention \\
\hline $\begin{array}{l}\text { Blinding of outcome as- } \\
\text { sessment (detection bias) } \\
\text { All outcomes }\end{array}$ & Unclear risk & No mention \\
\hline $\begin{array}{l}\text { Incomplete outcome data } \\
\text { (attrition bias) } \\
\text { All outcomes }\end{array}$ & Unclear risk & $\begin{array}{l}\text { Numbers of participants who did not complete the trial is not clear and num- } \\
\text { bers do not appear to be consistent throughout the paper. Drop-outs are given } \\
\text { for different outcome measures }\end{array}$ \\
\hline $\begin{array}{l}\text { Selective reporting (re- } \\
\text { porting bias) }\end{array}$ & Unclear risk & $\begin{array}{l}\text { Information on outcomes not fully reported in methods, therefore uncertainty } \\
\text { about reporting bias }\end{array}$ \\
\hline Other bias & Low risk & Appears to be free from other forms of bias \\
\hline
\end{tabular}

\section{Kennedy 1992}

Methods

Study design: 3 centre cross-over RCT

- 3 interventions: A sodium chloride washout, B Suby G washout, C Solution R washout

- allocation by random number tables (i.e. to decide order in which 3 solutions administered)

Study duration: intervention duration: 12 weeks ( 1 week normal saline washout run-in period, $3 \times 3$

week washout phase with each solution, and 1 week normal saline washout between interventions)

Participants

Inclusion criteria: Elderly women in long-term geriatric care with long-term catheter in situ

Setting: 3 geriatric hospitals

Country: UK

Health status: Not stated

Number: 25 entered trial. 11 women lost to follow up ( 5 died, 3 catheters removed, 2 withdrawn by nursing staff, 1 discharged). 14 women completed full 12 weeks of trial

Age: mean age 82 years, range 65 years to 100 years

Sex: Female 
Other relevant Information: Catheter type and material not stated (type patient already wearing used); median duration catheter in situ at start of study: 12 months (range 1 month to 204 months)

Exclusion criteria: no exclusion criteria stated

Interventions
Intervention: Cross-over study of 3 washout treatments

Group A: 3 weeks of twice weekly $0.9 \%$ sodium chloride washout

Group B: 3 weeks of twice weekly Suby $\mathrm{G}$ washout (citric acid 3.23\%, light magnesium oxide $0.38 \%$, sodium bicarbonate $0.7 \%$, and disodium edetate $0.01 \%$ )

Group C: 3 weeks of twice weekly Solution R washout (citric acid 6\%, gluconolactone $0.6 \%$, light magnesium carbonate $2.8 \%$, disodium edetate $0.01 \%$ )

Other relevant information: Each washout administered by attaching $100 \mathrm{~mL}$ sterile pre-packed sachet to catheter and allowing to drain into bladder via gravity, clamped for 20 minutes to 30 minutes and then allowed to drain out. Catheters changed at weeks 1, 5, 9 and 12
Outcomes
- Bacteriuria: patients with bacteria observed in washout fluid at end of washout period: A 100\%, B 75\%, C 76\% (insufficient data presentation); conclusion was that treatment with acidic solutions did not prevent or reduce urease-producers

- Catheter blockage (definition of blocked catheter: eyes or lumen completely blocked, resulting in no flow of urine, definition of partially blocked catheter: still able to allow urine drainage): blocked catheters: A 18/44, B 14/29, C 7/27, partially blocked catheters: A 14/44, B 12/29, C 10/27, non-encrusted catheters: A 12/44, B 3/29, C 10/27 (in each case denominator = no. of catheters)

- Degree of visual encrustation: little difference between 3 treatments up to day 10 , after which Solution $\mathrm{R}$ did not reduce encrustation (insufficient data presentation)

- Mean episodes of bypassing per week: A 1.55, B 1.4, C 1.9 (insufficient data presentation); differences not statistically significant

- Catheter removal/replacement: mean days catheter in situ: A 16.3, B 14.3, C 14.2 (insufficient data presentation); no significant differences between groups; only 3 patients retained catheter for full length of each trial period

- Patients with red blood cells in washout fluid at end of washout period: A 21\%, B 17\%, C 14\% (insufficient data presentation), higher counts during treatment $B$

- Patients with urothelial cells in washout fluid at end of washout period: A 100\%, B 86\%, C 100\% (insufficient data presentation), some evidence of a significant difference in the changes over time within the 3 treatments $\left(\mathrm{Chi}^{2}(14)=22.5, \mathrm{P}=0.068\right)$ but proportions all consistently high thus unlikely to be clinically significant

\section{Other outcomes reported (not analysed within this review):}

- 1 patient developed haematuria following treatment with solution $\mathrm{C}$

- Type and volume of crystals observed in washout fluid: significantly more crystals found during saline washouts than during acidic solutions $\left(\mathrm{Chi}^{2}(2)=29.06, \mathrm{P}<0.001\right)$; struvite appeared significantly more often in the saline washouts than in the Suby $\mathrm{G}$ and Solution R washouts $\left(\mathrm{Chi}^{2}(2)=22.075, \mathrm{P}<0.001\right)$; uric acid crystals appeared with Suby $\mathrm{G}$ and Solution R; calcium oxalate was slightly more common in saline washouts than during the acidic treatments; urates were seen only during saline washouts; no difference between the 3 regimes at the end of each 3-week washout period

- White blood cells present in washout fluid: A 100\%, B 87\%, C 84\% (insufficient data presentation); no significant differences between the 3 treatments ( $P$ not reported)

\section{Notes}

\section{Funding source: Not stated}

- Analysis based on end-point data available

- Insufficient data to analyse any possible interactions involving treatment order

\section{Risk of bias}


Kennedy 1992 (Continued)

Random sequence genera- Low risk Random number tables used to determine the order of the solutions tion (selection bias)

\begin{tabular}{lll}
\hline $\begin{array}{l}\text { Allocation concealment } \\
\text { (selection bias) }\end{array}$ & Unclear risk & Procedure not described \\
\hline $\begin{array}{l}\text { Blinding of participants } \\
\text { and personnel (perfor- }\end{array}$ & Unclear risk & \\
mance bias) & & \\
All outcomes &
\end{tabular}

Blinding of outcome as- Unclear risk No information given

sessment (detection bias)

All outcomes

Incomplete outcome data Low risk Stated numbers and reasons for drop-outs/withdrawals
(attrition bias)

All outcomes

\begin{tabular}{lll}
\hline $\begin{array}{l}\text { Selective reporting (re- } \\
\text { porting bias) }\end{array}$ & Low risk & $\begin{array}{l}\text { All outcomes mentioned in methods appear in the results section. Protocol } \\
\text { was not reviewed so some uncertainty regarding reporting bias }\end{array}$ \\
\hline Other bias & Low risk & Appears to be free of other bias \\
\hline
\end{tabular}

Linsenmeyer 2014

Methods Study design: prospective, randomised, double-blind, cross-over, multicentre clinical study, 3 part study

Study duration: 4 weeks

Participants

Inclusion criteria: Aged 18 years and older, spinal cord injury or other neurogenic bladder patient requiring a chronic indwelling urinary catheter with a history of 2 episodes of catheter blockage and/or encrustation, and urine $\mathrm{pH} \geq 6.5$

Setting: Not stated

Country: USA

Health status: Not stated

Number: 7 participants: Part $1 \mathrm{~N}=20$, Part $2 \mathrm{~N}=28$, Part $3 \mathrm{~N}=19$

Age: Age of total group ( $\mathrm{N}=67$ years) mean 46.6 years (range $=21$ years to 81 years)

Sex: male $N=50(75 \%)$

Other relevant Information: Catheter type: transurethral N = 34 (51\%), suprapubic N = 33 (49\%)

Exclusion criteria: Antibiotics within 7 days, current infections, recent history of autonomic dysreflexia

- Part 1: $0.2 \%$ auriclosene in preliminary formulation dosed over 2 weeks (3 times/week), Part 2: auriclosene dosed on same schedule as part 1, Part 3: auriclosene dosed for 4 weeks (2 times/week). The control for all parts was $0.9 \% \mathrm{w} / \mathrm{v}$ saline

- Participants randomised to one irrigation solution for the first treatment regimen and after a washout period, irrigated with the other solution. A single treatment consisted of 2 sequential irrigations of 25 $\mathrm{mL}$ retained in the catheter for 15 minutes 
Linsenmeyer 2014 (Continued)

Outcomes $\quad$ Results are given from Part 3 of the study ( $\mathrm{N}=14$ completed) only:

- Mean \% encrustation 'catheter patency' (95\% CI): Auriclosene group 21.7 (2.1, 41.2), Saline group 76.9 $(54.9,98.8)$. Catheter luminal encrustations documented by computerised microscopic assessment

- Percent of catheters removed for clinical blockage: Auriclosene group 14.3\%, Saline group 64.3\%

- Percent of removed catheters that have $100 \%$ encrustation: Auriclosene group $0 \%$, Saline group $64.3 \%$

Notes

Funding source: NovaBay Pharmaceuticals

- Numbers of participants completing parts 1,2 and 3 were 14, 20 and 14 respectively

- Further details of this study were found from the Clinical trials document (ClinicalTrials.gov: NCT01243125) and the pharmaceutical company responsible for the trial. Where appropriate, data has been used from these documents to augment the Linsenmeyer 2014 abstract.

- Unclear how the data were analysed and whether analysis was appropriate for cross-over trial design. Implied that the degree of encrustation data were analysed by group (i.e. all catheters after auriclosene vs all catheters after saline), and also within subject (i.e. paired analysis comparing each individual's encrustation after auriclosene and after saline)

\section{Risk of bias}

\begin{tabular}{|c|c|c|}
\hline Bias & Authors' judgement & Support for judgement \\
\hline $\begin{array}{l}\text { Random sequence genera- } \\
\text { tion (selection bias) }\end{array}$ & Unclear risk & Randomisation generation not reported \\
\hline $\begin{array}{l}\text { Allocation concealment } \\
\text { (selection bias) }\end{array}$ & Unclear risk & Randomisation concealment not reported \\
\hline $\begin{array}{l}\text { Blinding of participants } \\
\text { and personnel (perfor- } \\
\text { mance bias) } \\
\text { All outcomes }\end{array}$ & Low risk & $\begin{array}{l}\text { Described as double-blinded in ClinicalTrials.gov: NCT01243125. As this trial } \\
\text { compared one washout versus another, this would have been possible in this } \\
\text { trial }\end{array}$ \\
\hline $\begin{array}{l}\text { Blinding of outcome as- } \\
\text { sessment (detection bias) } \\
\text { All outcomes }\end{array}$ & Unclear risk & No information given \\
\hline $\begin{array}{l}\text { Incomplete outcome data } \\
\text { (attrition bias) } \\
\text { All outcomes }\end{array}$ & Unclear risk & $\begin{array}{l}\text { No details provided although the number of drop-outs per part of study can be } \\
\text { calculated }\end{array}$ \\
\hline $\begin{array}{l}\text { Selective reporting (re- } \\
\text { porting bias) }\end{array}$ & Low risk & The outcomes mentioned in the methods section were reported in the results \\
\hline Other bias & Low risk & Appears to be free of other bias \\
\hline
\end{tabular}

McNicoll 2003

Methods Study design: Single centre parallel group RCT with 2 groups: Group A - citric acid catheter maintenance solutions (CMS), Group B - planned catheter changes

Study duration: 12 weeks

Participants

Inclusion criteria: Community-based patients with long-term catheters known to block with encrustation 
McNicoll 2003 (Continued)

\section{Setting: Community \\ Country: UK}

Health status: Not stated

Number: 11 participants enrolled in trial (number allocated to each group not stated), 7 participants lost to follow-up (reasons not stated), 4 patients analysed (Group A N = 1, Group B N = 3)

Age: Not stated

Sex: Not stated

Other relevant Information: urethral catheters, material not stated, duration catheter in situ at start of study not stated

Exclusion criteria: Not stated

\begin{tabular}{ll}
\hline Interventions & Group A: daily instillation of citric acid CMS, volume used and method of administration not stated \\
& (108 patient contacts) \\
- Group B: planned catheter removal (approximately 55 patient contacts). Planned catheter change in- \\
tervention varied: 1 patient had catheter changed twice a week, 1 patient had catheter changed when \\
it showed signs of blocking, 1 patient had weekly pH tests and had catheter changed at beginning and \\
end of the study
\end{tabular}

Notes

Funding source: Not stated

- Analysis based on end point data available

\section{Risk of bias}

\begin{tabular}{lll}
\hline Bias & Authors' judgement & Support for judgement \\
\hline $\begin{array}{l}\text { Random sequence genera- } \\
\text { tion (selection bias) }\end{array}$ & Unclear risk & No information given \\
\hline
\end{tabular}

\begin{tabular}{lll}
\hline $\begin{array}{l}\text { Allocation concealment } \\
\text { (selection bias) }\end{array}$ & Unclear risk & No information given \\
\hline $\begin{array}{l}\text { Blinding of participants } \\
\text { and personnel (perfor- } \\
\text { mance bias) }\end{array}$ & High risk & $\begin{array}{l}\text { No mention of blinding but not possible in a trial of washout versus catheter } \\
\text { change }\end{array}$ \\
All outcomes & \\
\hline
\end{tabular}

\begin{tabular}{|c|c|c|}
\hline $\begin{array}{l}\text { Blinding of outcome as- } \\
\text { sessment (detection bias) } \\
\text { All outcomes }\end{array}$ & Unclear risk & No information given \\
\hline
\end{tabular}

Incomplete outcome data Unclear risk Stated numbers only (no reasons given)
(attrition bias)
All outcomes

\begin{tabular}{|c|c|c|}
\hline $\begin{array}{l}\text { Selective reporting (re- } \\
\text { porting bias) }\end{array}$ & High risk & $\begin{array}{l}\text { Methods state that symptomatic UTI rates would be monitored. These data } \\
\text { were not reported in the results and no reasons were provided }\end{array}$ \\
\hline
\end{tabular}


McNicoll 2003 (Continued)

Other bias Low risk Appears to be free of other biases

Moore 2009

Methods Study design: Parallel group RCT, 3 groups: catheter flush with saline vs acidic solution vs standard care (no washout)

Study duration: 8 weeks

Participants Inclusion criteria: Indwelling catheter in situ longer than 30 days, regular blocker that required
catheter changed every 3 weeks or less

Setting: Long-term care setting or received home care

Country: Canada

Health status: Sufficiently alert according the mini-mental state examination (MMSE score > 24)

Number: 73 enrolled, 53 completed

Age: Mean age 66.24 years (Contisol group mean 63.92 years, saline group mean 66.24 years, control group mean 68.56 years)

\section{$\operatorname{Sex}(\mathbf{m} / \mathbf{f}): 36 / 37$}

Exclusion criteria: Symptomatic UTI (individuals were eligible for the study following successful treatment of the UTI after a symptom-free period of 14 days); urethral erosion allowing continuous bypassing (leakage) around urinary catheter; history of bladder cancer, or radiation or interstitial cystitis; impaired renal function as evidenced by a serum creatinine level of $2.0 \mathrm{mg} / \mathrm{dL}$ or higher; gross haematuria; or indwelling catheter that was changed less frequently than every 8 weeks

- Group B: 8 weeks of weekly washout with $50 \mathrm{~mL}$ sterile normal saline washout

- Group C: 8 weeks of weekly washout with $50 \mathrm{~mL}$ sterile Contisol solution (containing citric acid 3.23\%, light magnesium oxide $0.38 \%$, sodium bicarbonate $0.7 \%$, and disodium edetate $0.01 \%$ )

\section{Outcomes}

- Mean time to first catheter change: Contisol 4.57 (SD 2.61) ( $N=19)$, saline 5.18 (SD 2.90) $(N=16)$, no washout 4.55 (SD 2.91) $(\mathrm{N}=20)$

- Incidence of symptomatic UTI (defined as at least one of five indications with no other recognised cause: fever $\geq 38$ degrees $C$, urgency, dysuria or suprapubic tenderness, haematuria or positive urine culture ( $\geq 100,000$ micro-organisms per cc of urine with no more than two species of microorganisms). None were detected in any group: Contisol 0/17, saline $0 / 16$, control 0/20.

- Incidence of microscopic haematuria. All participants had haematuria consistently (no data provided).

- Incidence of microscopic leukocytes. All participants had haematuria consistently (no data provided).

- Urine pH: mean pH 6.3 (SD 1.04) (range 5 to 8.5), not reported for groups

- Measurement of cross sectional catheter lumen. slicing of first 50 catheters supported the theory that biofilm or encrustations begins at the catheter tip, first at the eyes, proceeding down the shaft. \% of catheters with encrustation was low and the majority were obstructed with thick biofilm

Notes

Funding source: Alberta Heritage Foundation for Medical Research and the Canadian Nurses Foundation

- Cross sectional measurement of catheter was abandoned as the method did not prove useful for comparing effectiveness of washouts

- Data on all available patients was included in the Kaplan Meier analysis of time to first catheter change (with censoring when an individual withdrew, died, had a UTI treated with antibiotics, etc), however results on mean time to first catheter change are based on data for those who completed the trial only 
Moore 2009 (Continued)

- Authors gave reviewers access to data for further analysis

\section{Risk of bias}

\begin{tabular}{|c|c|c|}
\hline Bias & Authors' judgement & Support for judgement \\
\hline $\begin{array}{l}\text { Random sequence genera- } \\
\text { tion (selection bias) }\end{array}$ & Low risk & Computer generated random numbers \\
\hline $\begin{array}{l}\text { Allocation concealment } \\
\text { (selection bias) }\end{array}$ & Low risk & Group allocation placed in opaque envelope, opened by participant \\
\hline $\begin{array}{l}\text { Blinding of participants } \\
\text { and personnel (perfor- } \\
\text { mance bias) } \\
\text { All outcomes }\end{array}$ & High risk & $\begin{array}{l}\text { Blinding of the participants to washout type attempted, not possible to blind } \\
\text { the research nurse due to nature of the intervention and the packaging of } \\
\text { washouts }\end{array}$ \\
\hline $\begin{array}{l}\text { Blinding of outcome as- } \\
\text { sessment (detection bias) } \\
\text { All outcomes }\end{array}$ & Unclear risk & No information given. Assumed not done \\
\hline $\begin{array}{l}\text { Incomplete outcome data } \\
\text { (attrition bias) } \\
\text { All outcomes }\end{array}$ & Low risk & Stated numbers and reasons \\
\hline $\begin{array}{l}\text { Selective reporting (re- } \\
\text { porting bias) }\end{array}$ & Low risk & All outcomes mentioned in methods section were reported in the results \\
\hline Other bias & Low risk & Appears to be free of other biases \\
\hline
\end{tabular}

Muncie 1989

Methods Study design: Single centre cross-over RCT, 2 interventions: Group A: normal saline irrigation, Group B: no irrigation

Study duration: 24 weeks (2-week no irrigation run-in period, 2 x 10 week irrigation/no irrigation phase, and 2-week no-irrigation washout period before entering alternate phase)

Participants

Inclusion criteria: Indwelling catheter in situ > 30 days, Females aged 18 years +, were afebrile (temperature $\leq 37.7^{\circ}$ ) for 7 days, had not received antibiotics for 14 days

Setting: Hospital and medical centre

Country: USA

Health Status: Not stated

Number: 44 women entered the trial, 21 women did not complete the full intervention (10 died, 4 discharged, 3 catheter removed, 4 physician request), 23 women completed the 24 week intervention (A first 10, B first 13), 9 women completed at least one phase and five weeks of the second phase of the study

Age: mean age 71 years, range 37 years to 88 years, 33 women were aged 65 years or over

Sex: Female

Other relevant Information: Catheter type: double lumen, $18 \mathrm{~F}$, silicone-coated latex urethral catheters 
Exclusion criteria: Patients with malignant bladder neoplasms or patients whose physician insisted on continued bladder irrigation

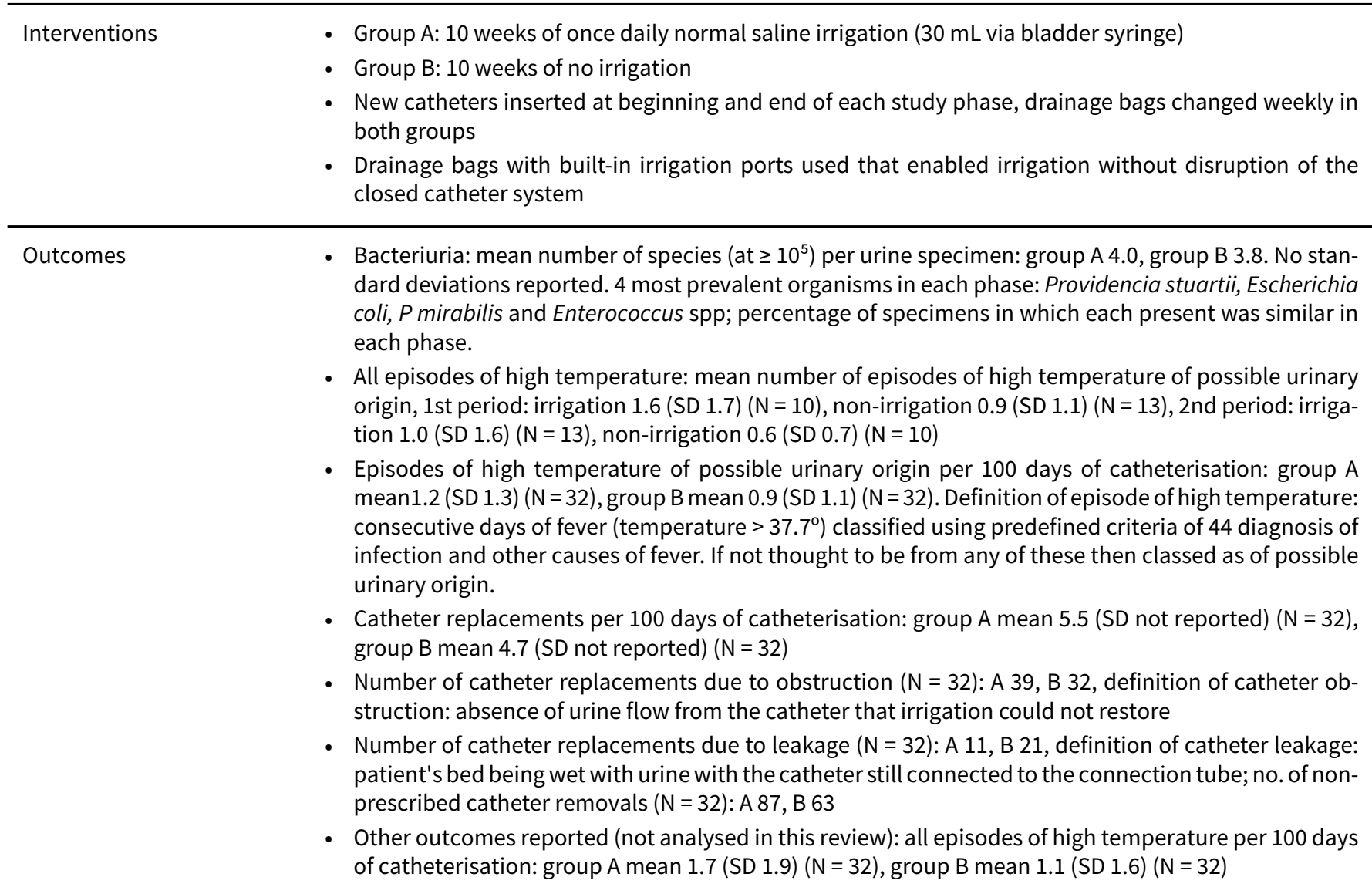

Notes

Funding source: National institute of Aging, National Institutes of Health

- Daily irrigations administered by trained nurse

- Routine catheter care included daily perineal cleansing with soap and water

- Number of non-protocol irrigations were similar during irrigation and non-irrigation periods

- Analysis based on end point data available

- 2 analyses carried out: patients completing all 24 weeks of the study, patients who completed one period and at least 5 weeks of the next period

\section{Risk of bias}

\begin{tabular}{|c|c|c|}
\hline Bias & Authors' judgement & Support for judgement \\
\hline $\begin{array}{l}\text { Random sequence genera- } \\
\text { tion (selection bias) }\end{array}$ & Unclear risk & States random assignment determined but no further details provided \\
\hline $\begin{array}{l}\text { Allocation concealment } \\
\text { (selection bias) }\end{array}$ & Unclear risk & No information given \\
\hline $\begin{array}{l}\text { Blinding of participants } \\
\text { and personnel (perfor- } \\
\text { mance bias) } \\
\text { All outcomes }\end{array}$ & High risk & $\begin{array}{l}\text { No mention of blinding. As a washout solution versus no washout, can assume } \\
\text { this was not possible }\end{array}$ \\
\hline
\end{tabular}


Muncie 1989 (Continued)
Blinding of outcome as-
Unclear risk
No information given sessment (detection bias)

All outcomes

Incomplete outcome data Low risk Stated numbers and reasons for drop-outs/withdrawals
(attrition bias)
All outcomes

\begin{tabular}{lll}
\hline $\begin{array}{l}\text { Selective reporting (re- } \\
\text { porting bias) }\end{array}$ & Low risk & All outcomes in methods were reported in results \\
\hline Other bias & Low risk & Appears to be free of other biases \\
\hline
\end{tabular}

Waites 2006

Methods Study design: parallel group RCT (double blind but no description given), 3 groups: Group A: normal saline irrigation, Group B: acetic acid irrigation, Group C: neomycin-polymyxin GU irrigation, groups stratified by sex

Study duration: 8 weeks

\begin{abstract}
Participants
Inclusion criteria: Community residing patients with neurogenic bladder managed by indwelling catheter, at least 6 months post spinal cord injury or onset of other neurological disease, evidence of microscopic bacteriuria and pyuria at time of study enrolment

Setting: Community

Country: USA

Health status: No other details provided

Number: 89 participants entered the trial (group A 29, group B 30, group C 30 ), 37 participants did not complete the full intervention ( 11 withdrew due to development of symptomatic UTI, 14 withdrew due to other health related reasons, 12 withdrew due to perceived difficulty, inconvenience or unwillingness to perform twice daily irrigations), 52 participants completed the intervention and were analysed (group A 21, group B 9, group C 22)
\end{abstract}

Age: mean age 45.8 years, range 19 years to 82 years

$\operatorname{Sex}(\mathbf{m} / \mathbf{f}): 49 / 40$

Exclusion criteria: patients with serious UTIs requiring systemic antibiotics or with prior renal function abnormalities, patients who had used an acidifying agent, bladder irrigant or systematic antibiotic in previous 7 days, and patients who were pregnant or unable/unwilling to give informed consent

Other relevant Information: no differences in demographic and injury related variables by group at baseline

- Years since injury or onset of disease significantly greater for participants who did not complete the study protocol

- Catheter type 71 Foley catheter, 18 suprapubic tube, catheter material not stated

- Duration catheter in situ pre-study enrolment not stated

Interventions

- group A: 8 weeks of twice daily normal saline irrigation

- group B: 8 weeks of twice daily $0.25 \%$ acetic acid irrigation

- group C: 8 weeks of twice daily neomycin-polymyxin GU irrigation containing $40 \mathrm{mg} / \mathrm{mL}$ neomycin sulphate and 200,000 units/mL polymyxin B

- $30 \mathrm{~mL}$ of each irrigant instilled for 20 minutes via bladder syringe 
Waites 2006 (Continued)

Outcomes
- Bacteriuria or pyuria in urine: no data reported at group level except for Enterococcus species (see below)

- Participants harbouring Enterococcus species alone or in conjunction with other types of bacteria after completing study: group A: $13 / 21$, group B: $7 / 9$, group C: 19/22

- Increased occurrence of enterococci over time significant for group C (P 0.02) (data reported graphically hence unable to determine exact values by group)

- Participants discontinuing use of irrigation due to development of symptomatic UTI: group A: 1/29, group B: $6 / 30$, group C: $4 / 30$

- Adverse effects: bladder spasms attributed directly to participation in bladder irrigation: group A 0/29, group B $1 / 30$, group C 2/30

- Other outcomes reported (not analysed in this review): generation of antimicrobial-resistant organisms, urinary $\mathrm{pH}$, urinary leukocytes

Notes

Funding source: Paralyzed Vetrans of America Spinal Cord Research Foundation

- First irrigation shown to patient in clinic setting, remaining irrigations administered at home by participant or carer

- Participants advised to continue usual practices for perineal hygiene and catheter care

- Drop-out rate in group B significantly higher than other two groups

- Analysis based on end point data available

- Data analysis combined patients with urethral and suprapubic catheters (author contacted to request results separately for these groups however with no success)

\section{Risk of bias}

\begin{tabular}{|c|c|c|}
\hline Bias & Authors' judgement & Support for judgement \\
\hline $\begin{array}{l}\text { Random sequence genera- } \\
\text { tion (selection bias) }\end{array}$ & Unclear risk & States that participants randomised but no further details provided \\
\hline $\begin{array}{l}\text { Allocation concealment } \\
\text { (selection bias) }\end{array}$ & Unclear risk & No information given \\
\hline $\begin{array}{l}\text { Blinding of participants } \\
\text { and personnel (perfor- } \\
\text { mance bias) } \\
\text { All outcomes }\end{array}$ & Unclear risk & Study described as double blinded but further details not provided \\
\hline $\begin{array}{l}\text { Blinding of outcome as- } \\
\text { sessment (detection bias) } \\
\text { All outcomes }\end{array}$ & Unclear risk & No information given \\
\hline $\begin{array}{l}\text { Incomplete outcome data } \\
\text { (attrition bias) } \\
\text { All outcomes }\end{array}$ & Low risk & Stated numbers and reasons for drop-outs/withdrawals \\
\hline $\begin{array}{l}\text { Selective reporting (re- } \\
\text { porting bias) }\end{array}$ & Low risk & All outcomes in methods reported in results \\
\hline Other bias & Low risk & Appears to be free of other biases \\
\hline
\end{tabular}

Characteristics of excluded studies [ordered by study ID] 


\begin{tabular}{ll}
\hline Study & Reason for exclusion \\
\hline Andersson 1986 & $\begin{array}{l}\text { Primary outcomes of interest to review (i.e. catheter-associated infection and encrustation) not ad- } \\
\text { dressed. Outcomes studied related to cleansing of bladder rather than catheter blockage from pus, } \\
\text { fibrin, necrotic tissue and blood clots }\end{array}$ \\
\hline
\end{tabular}

\begin{tabular}{ll} 
Bach 1990 & Not long-term catheterisation. RCT of citric acid versus saline to prevent catheter encrustation \\
\hline Bruun 1978 & $\begin{array}{l}\text { Unable to determine duration of catheterisation. RCT (cross-over design) of four irrigating solu- } \\
\text { tions: saline, } 0.25 \% \text { acetic acid, } 0.02 \% \text { chlorhexidine, } 0.25 \% \text { silver nitrate }\end{array}$ \\
\hline Davies 1987 & $\begin{array}{l}\text { Not all patients catheterised for more than } 28 \text { days. RCT of chlorhexidine versus saline on urinary } \\
\text { bacterial count. } 48 \text { patients catheterised for } 3 \text { weeks or more. Unable to separate data of patients } \\
\text { who met inclusion criteria for this trial }\end{array}$ \\
\hline Elliott 1989 & $\begin{array}{l}\text { Study methods insufficiently described and insufficient data reported on the effect on bacteruria in } \\
\text { treatment and control groups. Thus the study was excluded as it did not contribute information on } \\
\text { any of the reviews primary outcome measures, rather it focused on urothelial exfoliations rates and } \\
\text { presented these data only graphically. RCT (cross-over design) of effect of washouts (2.5\% noxythi- } \\
\text { olin or saline) on the urothelium }\end{array}$
\end{tabular}

Elliott 1990

Unable to determine if patients randomised. Study methods insufficiently described. Insufficient data reported for calculating the effect on bacteruria in treatment and control groups

\section{Furuno 1998}

Not an RCT. Comparison of irrigation with super oxidation water and normal saline in 21 paraplegics (conference abstract at 33rd Annual Meeting of Japan Medical Society of Paraplgia 1998)

\section{Gelman 1980}

Not clear that this is an RCT. Duration of catheterisation at start of study less than 28 days for some patients. Comparison of three methods of irrigation with $0.25 \%$ acetic acid (no irrigation, one irrigation a week, two irrigations per day)

\begin{tabular}{ll}
\hline Kennedy 1984 & Not an RCT. Cross-over study of saline versus two Uro-tainer solutions \\
\hline Meyers 1964 & $\begin{array}{l}\text { Not all patients catheterised for more than } 28 \text { days. Analysis of long-term catheterised patients not } \\
\text { reported. RCT of nitrofurazone and neomycin/polymyxin for prevention of bacteriuria }\end{array}$ \\
\hline Robertson 1990 & $\begin{array}{l}\text { Not an RCT. Comparison of effect of mandelic acid on two different bacterial species. There was on- } \\
\text { ly a single group of subjects who received a single regimen of } 1 \% \text { mandelic acid }\end{array}$ \\
\hline Ruwaldt 1983 & $\begin{array}{l}\text { Unable to determine if RCT. Cross-over comparison of twice daily irrigations with Suby G versus no } \\
\text { irrigations }\end{array}$ \\
\hline Vainrub 1977 & $\begin{array}{l}\text { Comparison with intermittent catheterised patients not relevant to review. Comparison of effect } \\
\text { of methenamine mandelate and ascorbic acid on bacteriuria between indwelling and intermittent } \\
\text { catheterised patients }\end{array}$ \\
\hline Warren 1978 & $\begin{array}{l}\text { Not long-term catheterisation. RCT of neomycin-polymyxin irrigation versus no irrigation for pre- } \\
\text { vention of UTls }\end{array}$ \\
\hline
\end{tabular}

\section{Characteristics of ongoing studies [ordered by study ID]}

\section{NCT02130518}

\begin{tabular}{ll}
\hline Trial name or title & Efficacy study of auriclosene irrigation solution on urinary catheter patency \\
\hline Methods & Multicentre, randomised, double blind \\
\hline
\end{tabular}


NCT02130518 (Continued)

Participants

Estimated enrolment of 140 participants. Inclusion criteria: aged 18 years and older, history of catheter blockage and/or encrustation. Exclusion criteria: systemic antibiotic use within 14 days of first treatment, current infection
Experimental group: Auriclosene irrigation solution 0.2\%, 8 treatments over 4 weeks

Placebo group: Auriclosene Vehicle solution, 8 treatments over 4 weeks

\begin{tabular}{ll}
\hline Outcomes & Percent flow rate of catheters at time of removal \\
& Number of catheters removed due to blockage \\
& Number of subjects with serious and non-serious adverse events \\
\hline Starting date & September 2014 \\
\hline Contact information & nocampo@novabay.com \\
\hline Notes & Estimated completion date December 2016 \\
& Authors contacted in October 2015 but no results were available at that time
\end{tabular}

\section{DATA AND ANALYSES}

\section{Comparison 1. Any washout versus no washout}

\begin{tabular}{|c|c|c|c|c|}
\hline Outcome or subgroup title & No. of studies & $\begin{array}{l}\text { No. of partici- } \\
\text { pants }\end{array}$ & Statistical method & Effect size \\
\hline $\begin{array}{l}1 \text { Number of participants with } \\
\text { symptomatic UTI }\end{array}$ & 1 & & Risk Ratio (M-H, Fixed, 95\% Cl) & $\begin{array}{l}\text { Totals not select- } \\
\text { ed }\end{array}$ \\
\hline 1.1 any washout versus no washout & 1 & & Risk Ratio (M-H, Fixed, 95\% Cl) & $0.0[0.0,0.0]$ \\
\hline $\begin{array}{l}1.2 \text { saline washout versus no } \\
\text { washout }\end{array}$ & 1 & & Risk Ratio (M-H, Fixed, 95\% Cl) & $0.0[0.0,0.0]$ \\
\hline $\begin{array}{l}1.3 \text { citric acid washout versus no } \\
\text { washout }\end{array}$ & 1 & & Risk Ratio (M-H, Fixed, 95\% Cl) & $0.0[0.0,0.0]$ \\
\hline 2 weeks to first catheter change & 1 & & $\begin{array}{l}\text { Mean Difference (IV, Fixed, 95\% } \\
\mathrm{CI})\end{array}$ & $\begin{array}{l}\text { Totals not select- } \\
\text { ed }\end{array}$ \\
\hline 2.1 any washout versus no washout & 1 & & $\begin{array}{l}\text { Mean Difference (IV, Fixed, 95\% } \\
\mathrm{CI})\end{array}$ & $0.0[0.0,0.0]$ \\
\hline $\begin{array}{l}2.2 \text { saline washout versus no } \\
\text { washout }\end{array}$ & 1 & & $\begin{array}{l}\text { Mean Difference (IV, Fixed, 95\% } \\
\mathrm{CI})\end{array}$ & $0.0[0.0,0.0]$ \\
\hline $\begin{array}{l}2.3 \text { citric acid washout versus no } \\
\text { washout }\end{array}$ & 1 & & $\begin{array}{l}\text { Mean Difference (IV, Fixed, 95\% } \\
\mathrm{CI})\end{array}$ & $0.0[0.0,0.0]$ \\
\hline $\begin{array}{l}3 \text { Number of participants needing } \\
\text { catheter replacement }\end{array}$ & 1 & & Risk Ratio (M-H, Fixed, 95\% Cl) & Subtotals only \\
\hline
\end{tabular}




\begin{tabular}{lllll}
\hline Outcome or subgroup title & No. of studies & $\begin{array}{l}\text { No. of partici- } \\
\text { pants }\end{array}$ & Statistical method & Effect size \\
\hline $\begin{array}{l}3.1 \text { saline washout versus no } \\
\text { washout }\end{array}$ & 1 & 40 & Risk Ratio (M-H, Fixed, 95\% Cl) & $0.67[0.34,1.31]$ \\
\hline $\begin{array}{l}4 \text { Mean number of episodes of high } \\
\text { temperature }\end{array}$ & 1 & Mean Difference (Fixed, 95\% & Subtotals only \\
\hline $\begin{array}{l}5 \text { Mean number of episodes of high } \\
\text { temperature of poss urinary origin }\end{array}$ & 1 & Mean Difference (Fixed, 95\% & $\begin{array}{l}\text { Totals not select- } \\
\text { ed }\end{array}$ \\
\hline
\end{tabular}

Analysis 1.1. Comparison 1 Any washout versus no washout, Outcome 1 Number of participants with symptomatic UTI.

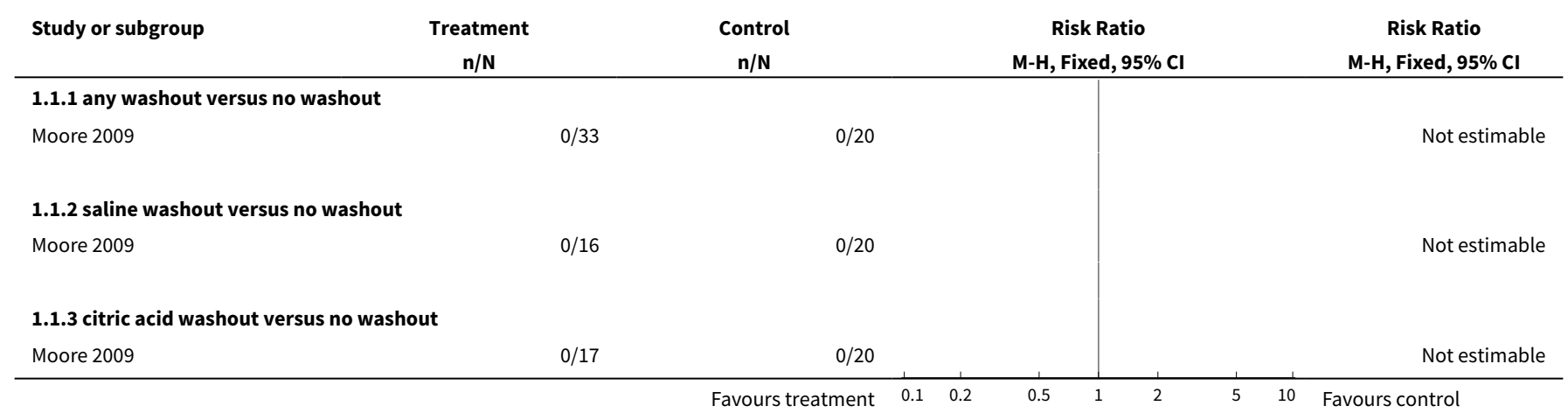

\section{Analysis 1.2. Comparison 1 Any washout versus no washout, Outcome 2 weeks to first catheter change.}

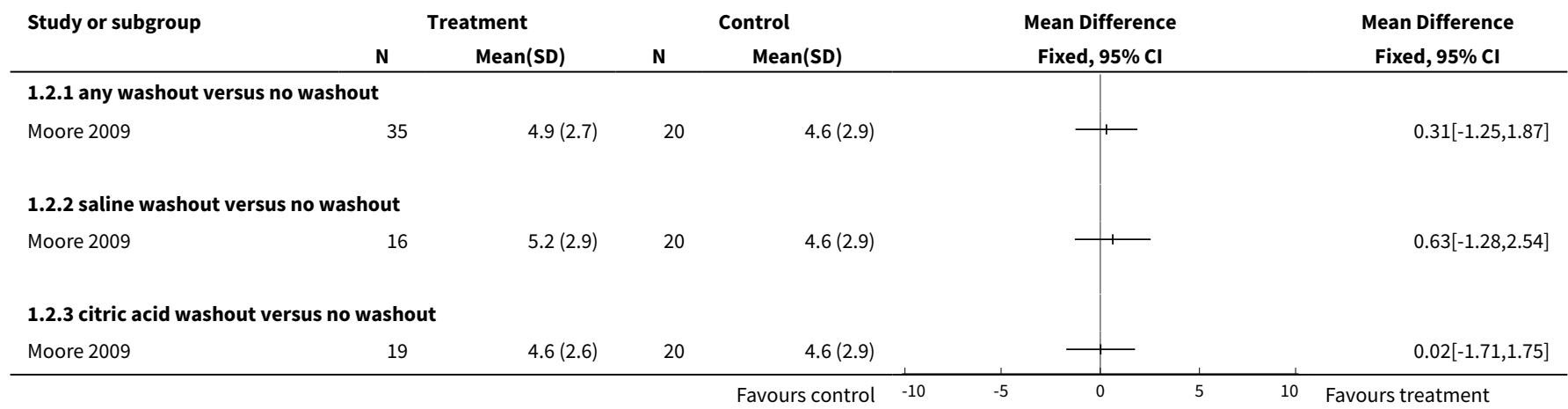

Analysis 1.3. Comparison 1 Any washout versus no washout, Outcome 3 Number of participants needing catheter replacement.

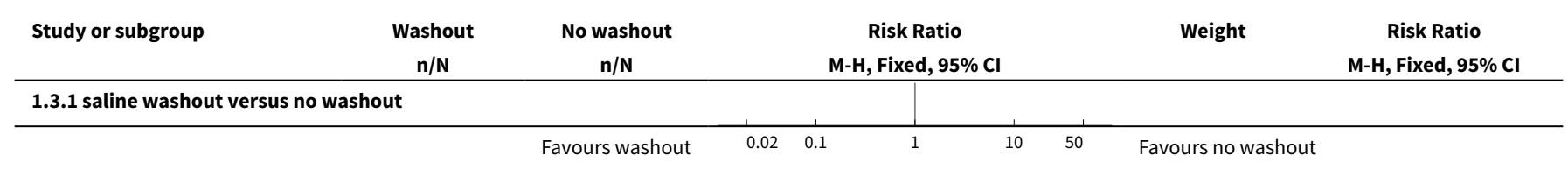




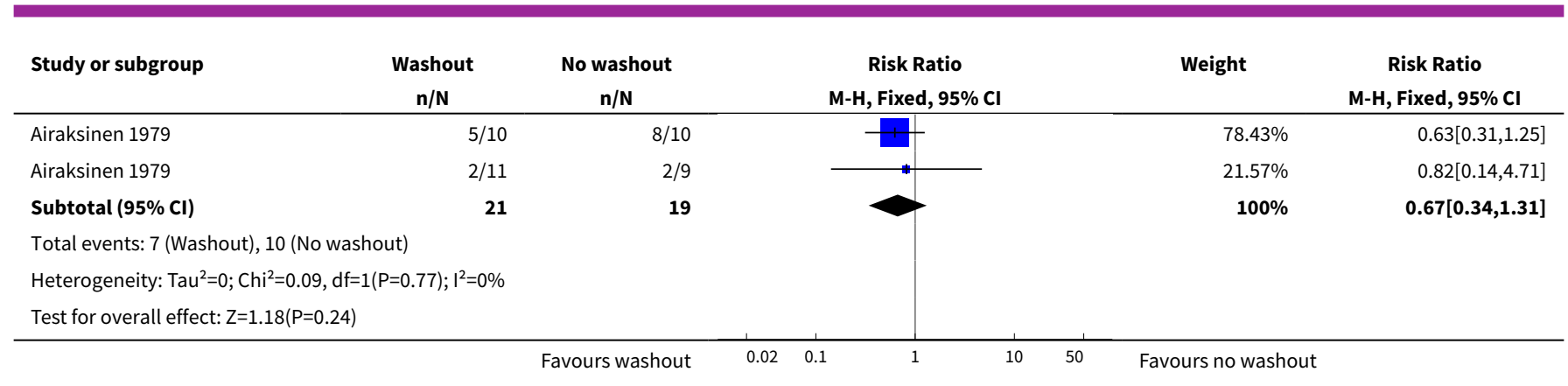

Analysis 1.4. Comparison 1 Any washout versus no washout, Outcome 4 Mean number of episodes of high temperature.

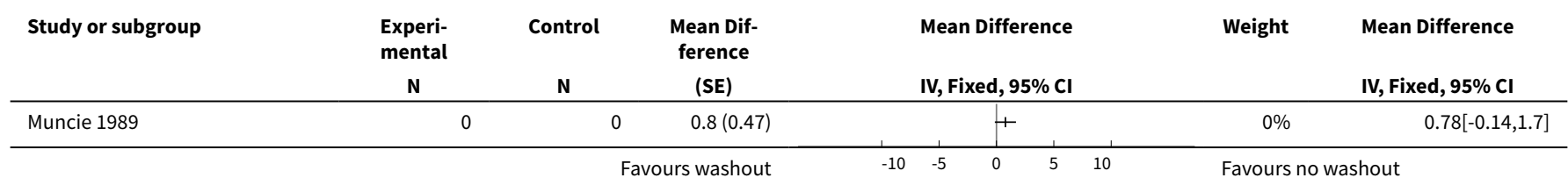

Analysis 1.5. Comparison 1 Any washout versus no washout, Outcome 5 Mean number of episodes of high temperature of poss urinary origin.

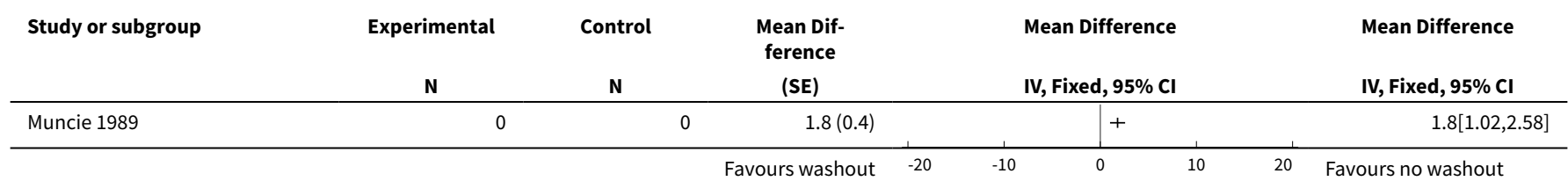

Comparison 2. One washout solution versus another

\begin{tabular}{lllll}
\hline Outcome or subgroup title & No. of studies & $\begin{array}{l}\text { No. of partici- } \\
\text { pants }\end{array}$ & Statistical method & Effect size \\
\hline $\begin{array}{l}1 \text { Number of participants with } \\
\text { symptomatic UTI }\end{array}$ & 1 & Risk Ratio (M-H, Fixed, 95\% Cl) & $\begin{array}{l}\text { Totals not select- } \\
\text { ed }\end{array}$ \\
\hline $\begin{array}{llll}1.1 \text { citric acid verus saline } \\
\text { 2 weeks to first catheter change }\end{array}$ & 1 & Risk Ratio (M-H, Fixed, 95\% CI) & $0.0[0.0,0.0]$ \\
\hline 2.1 citric acid verus saline & 1 & $\begin{array}{l}\text { Mean Difference (IV, Fixed, 95\% } \\
\text { Cl) }\end{array}$ & $\begin{array}{l}\text { Totals not select- } \\
\text { ed }\end{array}$ \\
\hline
\end{tabular}




\section{Analysis 2.1. Comparison 2 One washout solution versus another,} Outcome 1 Number of participants with symptomatic UTI.

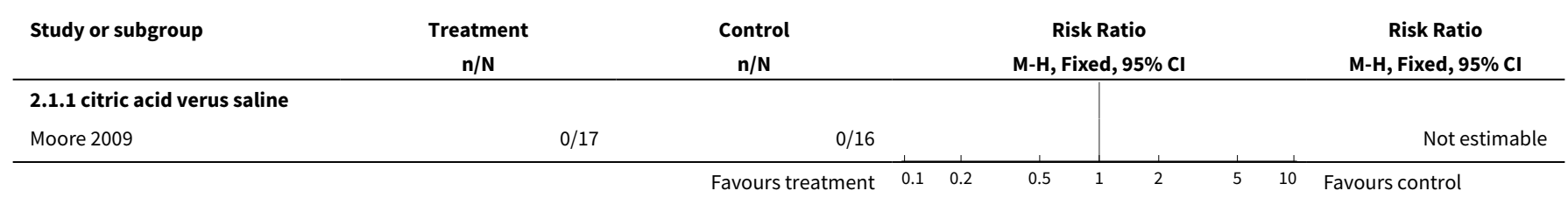

Analysis 2.2. Comparison 2 One washout solution versus another, Outcome 2 weeks to first catheter change.

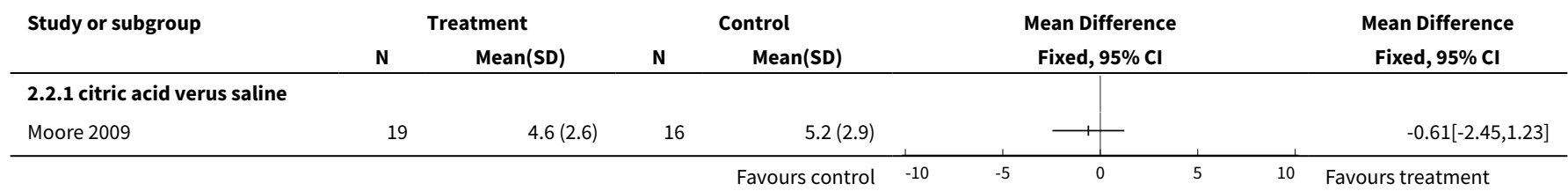

\section{APPENDICES}

\section{Appendix 1. Search strategies for 2017 review update}

The Cochrane Incontinence Specialised Register was searched using the Group's own keyword system. The search terms used were:

(\{design.cct* ${ }^{\star}$ OR $\left\{\right.$ design.rct $\left.\left.{ }^{\star}\right\}\right)$

AND

\{INTVENT.MECH.CATH.MaintenanceSolutions $\left.{ }^{\star}\right\}$ )

(All searches were of the keyword field of Reference Manager 2012)

\section{Appendix 2. Search strategies used for 2010 review}

For the first published version of this review (Hagen 2010) we searched the Cochrane Incontinence Specialised Trials Register (searched 30 April 2009), MEDLINE (January 1966 to April 2009), MEDLINE In-Process (30 April 2009), EMBASE (January 1980 to April 2009) and CINAHL (December 1981 to April 2009). Additionally, we examined all reference lists of identified trials and contacted manufacturers and researchers in the field.

The Incontinence Group Specialised Register was searched using the Group's own keyword system. The search terms used were:

(\{design.cct OR \{design.rct\})

AND

(\{intvent.mech.cath.washout $\left.{ }^{\star}\right\}$ OR \{intvent.mech.cath.irrigation*\} OR \{intvent.prevent.cath $\left.\left.{ }^{\star}\right\}\right)$

(All searches were of the keyword field of Reference Manager $9.5 \mathrm{~N}$, ISI ResearchSoft).

For this first version of the review specific extra searches were performed by the review authors (Hagen 2010). These are detailed below:

- MEDLINE (January 1966 to April 2009),

- MEDLINE In-Process (searched on 30 April 2009),

- EMBASE (January 1980 to Week 17 2009) was searched on 27 April 2009,

- CINAHL on OVID (1982 to July Week 12007 ) was searched on 18 July 2007,

- CINAHL on EBSCO (December 1981 to Week 4 April 2009) was searched on 28 April 2009.

These databases were searched by the review authors using appropriate free text and MeSH terms/EMTREE terms/controlled vocabulary. This was done by adapting terms drawn from the existing search strategies of the Cochrane Incontinence group to meet the objectives of this review. Full details of the search terms used are given below: 


\section{MEDLINE and MEDLINE In-Process \& Other Non-Indexed Citations on OVID}

1. Irrigation/

2. (bladder adj5 irrigat\$).mp. [mp=title, original title, abstract, name of substance word, subject heading word]

3. bladder washout\$.mp.

4. (catheter\$ adj5 irrigat\$).mp. [mp=title, original title, abstract, name of substance word, subject heading word]

5. (catheter\$ adj3 maintenanc\$).mp. [mp=title, original title, abstract, name of substance word, subject heading word]

6. catheter blockage\$.mp.

7. Crystallization/

8. encrustation\$.mp.

9. Anti-Bacterial Agents/ad, tu [Administration \& Dosage, Therapeutic Use]

10. Anti-Infective Agents/ad, tu [Administration \& Dosage, Therapeutic Use]

11. Antifungal Agents/ad, tu [Administration \& Dosage, Therapeutic Use]

12. Candidiasis/dt [Drug Therapy]

13. Bacteriuria/dt [Drug Therapy]

14. Bacteriuria/pc [Prevention \& Control]

15. or/1-14

16. catheters, Indwelling/

17. urinary catheter\$.mp. [mp=title, original title, abstract, name of substance word, subject heading word]

18. Urinary Catheterization/

19. ((long-term or long-term or longterm) adj2 catheter\$).mp. [mp=title, original title, abstract, name of substance word, subject heading word]

20. ((indwelling or in-dwelling) adj2 catheter\$).mp. [mp=title, original title, abstract, name of substance word, subject heading word]

21. bladder catheter\$.mp.

22. urethral catheter\$.mp.

23. or $/ 16-22$

24. Catheterization, Central Venous/

25. Postoperative Care/

26. Vascular Patency/

27. 24 or 25 or 26

28. 15 and 23

29. 28 not 27

This set of terms was combined with the first two parts of the Cochrane Highly Sensitive Search Strategy for identifying reports of randomised controlled trials in MEDLINE (Appendix 5b.2, Cochrane Reviewers Handbook, version 4.2, March 2003) using the Boolean operator 'AND'.

\section{CINAHL (ON OVID)}

1. "URINARY CATHETER IRRIGATION (SABA CCC)"/ or CATHETER IRRIGATION, URINARY/ or URINARY BLADDER IRRIGATION/ or irrigation.mp. or IRRIGATION/

2. (catheter\$ adj3 maintenanc\$).mp. [mp=title, subject heading word, abstract, instrumentation]

3. catheter blockage\$.mp.

4. encrustation\$.mp. or Catheter Occlusion/

5. Antiinfective Agents/ad, tu [Administration and Dosage, Therapeutic use]

6. Antifungal Agents/ad, tu [Administration and Dosage, Therapeutic use]

7. CANDIDIASIS/dt [Drug Therapy]

8. BACTERIURIA/pc, dt [Prevention and Control, Drug Therapy]

9. Catheter-Related Infections/pc, dt [Prevention and Control, Drug Therapy]

10.1 or 2 or 3 or 4 or 5 or 6 or 7 or 8 or 9

11. urinary catheterization.mp.

12. urinary catheterisation.mp. or Urinary Catheterization/

13. urinary catheter\$.mp. or Catheters, Urinary/

14. Catheter Care, Urinary/

15. (long-term adj2 catheter\$).mp.

16. bladder catheter\$.mp.

17. urethral catheter\$.mp.

18. 11 or 12 or 13 or 14 or 15 or 16 or 17

19. 10 and 18

This set of terms was combined with the sensitive search strategy for identifying reports of trials in CINAHL (developed by the Cochrane Stroke Group, available via OVID on the NHS eLibrary) using the Boolean operator 'AND'.

\section{CINAHL (on EBSCO)}

\section{\# Query}


S53 S52 and em 200707-

S52 S27 and S51

S51 S40 and S50

$\mathrm{S} 50 \mathrm{~S} 41$ or S42 or S43 or S44 or S45 or S46 or S47 or S48 or S49

S49 urethral catheter*

S48 bladder catheter ${ }^{\star}$

S47 (long-term or longterm) N2 catheter*

S46 (MH "Catheter Care, Urinary")

S45 (MH "Catheters, Urinary")

S44 urinary catheter*

S43 (MH "Urinary Catheterization")

S42 urinary catheterisation

S41 urinary catheterization

S40 S28 or S29 or S30 or S31 or S32 or S33 or S34 or S35 or S36 or S37 or S38 or S39

S39 (MH "Catheter-Related Infections/DT/PC")

S38 (MH "Bacteriuria/DT/PC")

S37 (MH "Candidiasis/DT")

S36 (MH "Antifungal Agents/AD/TU")

S35 (MH "Antiinfective Agents/AD/TU")

S34 encrustation*

S33 catheter* N3 blockage*

S32 catheter ${ }^{*}$ N3 maintenanc*

S31 Tl irrigation or AB irrigation

S30 (MH "Catheter Occlusion")

S29 (MH "Irrigation") or (MH "Urinary Bladder Irrigation")

S28 (MH "Catheter Irrigation, Urinary") or (MH "Urinary Catheter Irrigation (Saba CCC)")

S27 S26 or S25

S26 (MH "Comparative Studies")

$\mathrm{S} 25 \mathrm{~S} 1$ or S2 or S3 or S4 or S5 or S6 or S7 or S8 or S9 or S10 or S11 or S12 or S13 or S14 or S15 or S16 or S17 or S18 or S19 or S20 or S21 or S22 or S23 or S24

S24 (MH "Clinical Research+")

S23 (MH "Static Group Comparison")

S22 (MH "Quantitative Studies")

S21 (MH "Crossover Design") or (MH "Solomon Four-Group Design")

S20 (MH "Factorial Design")

S19 (MH "Community Trials")

S18 (MH "Random Sample")

S17 (MH "Random Assignment")

S16 TI balance ${ }^{*}$ N2 block* or AB balance* N2 block*

$\mathrm{S} 15 \mathrm{TI}$ "latin square" or AB "latin square"

S14 TI cross-over or AB cross-over

S13 TI crossover or AB crossover

S12 TI factorial or AB factorial

S11 TI ( tripl ${ }^{\star}$ N25 (blind ${ }^{\star}$ or mask ${ }^{\star}$ ) ) or AB ( tripl ${ }^{\star}$ N25 (blind ${ }^{\star}$ or mask $^{\star}$ ) )

$\mathrm{S} 10 \mathrm{TI}$ ( trebl* N25 (blind* or mask*) ) or AB ( trebl* N25 (blind* or mask*) )

S9 TI ( doubl* N25 (blind ${ }^{*}$ or mask $\left.{ }^{\star}\right)$ ) or AB (doubl* N25 (blind* or mask*) )

S8 TI ( singl ${ }^{\star}$ N25 (blind ${ }^{\star}$ or mask $\left.{ }^{\star}\right)$ ) or AB ( singl ${ }^{\star}$ N25 (blind* or mask*) )

S7 TI clin* N25 trial* or AB clin* N25 trial*

S6 (MH "Study Design")

S5 (AB random*) OR (TI random*)

S4 (AB placebo*) OR (TI placebo*)

S3 (MH "Placebos")

S2 PT Clinical Trial

S1 (MH "Clinical Trials+")

\section{Embase on OVID}

1. irrigation.mp. or BLADDER IRRIGATION/

2. (catheter\$ adj3 maintenanc\$).mp. [mp=title, subject heading word, abstract, instrumentation]

3. bladder washout\$.mp.

4. catheter blockage\$.mp.

5. encrustation\$.mp. or Catheter Occlusion/

6. Crystallization/ 
7. Antiinfective Agent/ad, do, dt [Drug Administration, Drug Dose, Drug Therapy]

8. Antifungal Agent/ad, do, dt [Drug Administration, Drug Dose, Drug Therapy]

9. antibacterial agent\$.mp.

10. CANDIDIASIS/dm, dt, th [Disease Management, Drug Therapy, Therapy]

11. BACTERIURIA/pc, dm, dt, th [Prevention, Disease Management, Drug Therapy, Therapy]

12. Catheter Infection/pc, dm, dt, th [Prevention, Disease Management, Drug Therapy, Therapy]

13. 1 or 2 or 3 or 4 or 5 or 6 or 7 or 8 or 9 or 10 or 11 or 12

14. Indwelling Catheter/

15. indwelling catheter\$.mp.

16. Urine Catheter/

17. urine catheter\$.mp.

18. urinary catheter\$.mp.

19. Suprapubic Catheter/

20. suprapubic catheter\$.mp.

21. suprapubic bladder catheterization/

22. (long-term adj2 catheter\$).mp.

23. Bladder Catheterization/

24. bladder catheter\$.mp.

25. urethral catheter\$.mp.

26.14 or 15 or 16 or 17 or 18 or 19 or 20 or 21 or 22 or 23 or 24 or 25

27.13 and 26

28. Postoperative Care/

29. Vascular Patency/

30. Central Venous Catheterization/

31.28 or 29 or 30

32. 27 not 31

This set of terms was combined with the Cochrane suggested search strategy for identifying reports of randomised controlled trials in EMBASE (available via OVID on the NHS eLibrary) using the Boolean operator 'AND'. An optimal strategy for EMBASE has not yet been tested and formally approved. However, the suggested strategy has been employed in searches for the Cochrane collaboration.

The UK National Research Register, Controlled Clinical Trials and ZETOC database of conference abstracts were searched on 17 October 2006 using various combinations of the following search terms: catheter, bladder, washout, maintenance, solution, irrigation, instillation, care, infection, bacteriuria, encrustation, blockage, occlusion, crystallisation, anti-infective agents, anti-bacterial agents.

\section{Searching other resources}

We placed calls for information about other possibly relevant trials on the Association for Continence Advice (ACA) website (March 2007), the ACA quarterly Journal (Volume 26 Issue 2 2007), and the weekly Update of Royal College of Nursing Research \& Development Coordinating Centre electronic bulletin (W/C 26 March 2007). Presentations were given at the 2007 RCN International Nursing Research Conference (April 2007), the 22nd Annual Scottish Task Force Symposium on Incontinence (May 2007) and the Scottish NMAHP Research into Practice Conference (October 2007) to inform others of this review and invite information on other possibly relevant studies.

WHAT'S NEW

\begin{tabular}{lll}
\hline Date & Event & Description \\
\hline 15 February 2017 & New search has been performed & $\begin{array}{l}\text { Updated review: two new included studies were added (Airaksi- } \\
\text { nen 1979; Linsenmeyer 2014). Conclusions are similar to the pre- } \\
\text { vious published version of the review (Hagen 2010). }\end{array}$ \\
\hline 15 February 2017 & $\begin{array}{l}\text { New citation required but conclusions } \\
\text { have not changed }\end{array}$ & $\begin{array}{l}\text { New citation: conclusions not changed. Updated search fully in- } \\
\text { corporated into the review. }\end{array}$
\end{tabular}

\section{HISTORY}

Protocol first published: Issue 1, 2003

Review first published: Issue 3, 2010 


\begin{tabular}{lll}
\hline Date & Event & Description \\
\hline 26 February 2010 & Amended & TSC comments amended \\
\hline
\end{tabular}

\section{CONTRIBUTIONS OF AUTHORS}

AS and SH independently assessed all titles and abstracts identified by the search strategy. AS, SH and WM completed the data extraction and quality assessment of all included trials. AS contacted authors of papers, and gathered additional data. SH was responsible for data entry, analysis and interpretation. WM provided clinical perspective and further interpretation. SH was the review guarantor.

\section{DECLARATIONS OF INTEREST}

Ashley Shepherd: None known.

Suzanne Hagen: None known.

William McKay: None known.

\section{SOURCES OF SUPPORT}

\section{Internal sources}

- No sources of support supplied

\section{External sources}

- National Institute for Health Research, UK.

This project was supported by the National Institute for Health Research, via Cochrane Infrastructure, Cochrane Programme Grant or Cochrane Incentive funding to the Incontinence Group. The views and opinions expressed therein are those of the authors and do not necessarily reflect those of the Systematic Reviews Programme, NIHR, NHS or the Department of Health.

\section{DIFFERENCES BETWEEN PROTOCOL AND REVIEW}

For the 2017 update of the review there was no additional searching of databases other than the Cochrane Incontinence Specialised Register as this now includes relevant searches of the Cochrane Central Register of Controlled Trials (CENTRAL), MEDLINE, MEDLINE InProcess, MEDLINE Epub Ahead of Print, CINAHL, ClinicalTrials.gov, WHO ICTRP, and UK Clinical Research Network Portfolio. Cochrane now organises centralised searches of Embase (including conference abstracts) that are included in CENTRAL so no additional Embase searches were performed. We continued to search the reference lists of relevant articles. The order of primary outcomes presented in the review has changed from the 2010 version following editors' advice.

\section{NDEX TERMS}

\section{Medical Subject Headings (MeSH)}

${ }^{\star}$ Catheters, Indwelling [statistics \& numerical data]; Device Removal; Equipment Failure; Randomized Controlled Trials as Topic; Solutions [*administration \& dosage] [chemistry]; Therapeutic Irrigation [adverse effects] [ ${ }^{*}$ methods]; Time Factors; Urinary Bladder Neck Obstruction [therapy]; Urinary Catheterization [*instrumentation]; Urinary Incontinence [therapy]

\section{MeSH check words}

Adult; Aged; Aged, 80 and over; Female; Humans; Male; Middle Aged 